\title{
Total Synthesis of the Nagelamides - Synthetic Studies Towards the Reported Structure of Nagelamide D and Nagelamide E Framework
}

Manojkumar R. Bhandari ${ }^{1}$, Apsara Herath ${ }^{1}$, Sivappa Rasapalli ${ }^{2}$, Muhammed Yousufuddin ${ }^{3}$, Carl J. Lovely ${ }^{1 *}$ ${ }^{1}$ Department of Chemistry and Biochemistry, The University of Texas of Arlington, Arlington, TX 760190065, USA

${ }^{2}$ Department of Chemistry and Biochemistry, University of Massachusetts Dartmouth, 285 Old Westport Rd, North Dartmouth, MA 02747, USA

${ }^{3}$ Life and Health Sciences Department, University of North Texas at Dallas, Dallas, TX 75241, USA

1. Ball and stick and ORTEP representations and structural parameters determined for X-ray structures of compounds 61 and $62-\mathrm{S} 2-\mathrm{S} 5$

2. Copies of ${ }^{1} \mathrm{H}$ NMR and ${ }^{13} \mathrm{C}$ NMR data for compounds 26, 28-31, 33-45, 49, 52-55, 7, 62, 67 - S6S61 


\section{Crystal Structure Determination}

Crystals were obtained by slow evaporation of solutions of the imidazole derivatives in ethyl acetate/hexane mixtures. Single crystal X-ray diffraction (SXRD) data for $\mathbf{6 1}$ and $\mathbf{6 2}$ were collected using a Bruker SMART APEX diffractometer with Mo- $K_{\alpha}$ radiation $(\lambda=0.71073 \AA)$. The cell parameters for were obtained from the least squares refinement of the spots (from 60 collected frames) using the SMART program. Data collection was performed using SMART and data processing was performed using the SAINT program. Initial atomic positions were located using direct methods. Calculated hydrogen atom positions were input and refined in a riding manner along with attached carbons. The crystallographic details for both compounds are summarized in the tables below. The structures have been deposited with the Cambridge Crystallographic Data Centre with the following accession numbers 2012579 for compound $\mathbf{6 1}$ and 2012587 for compound 62.
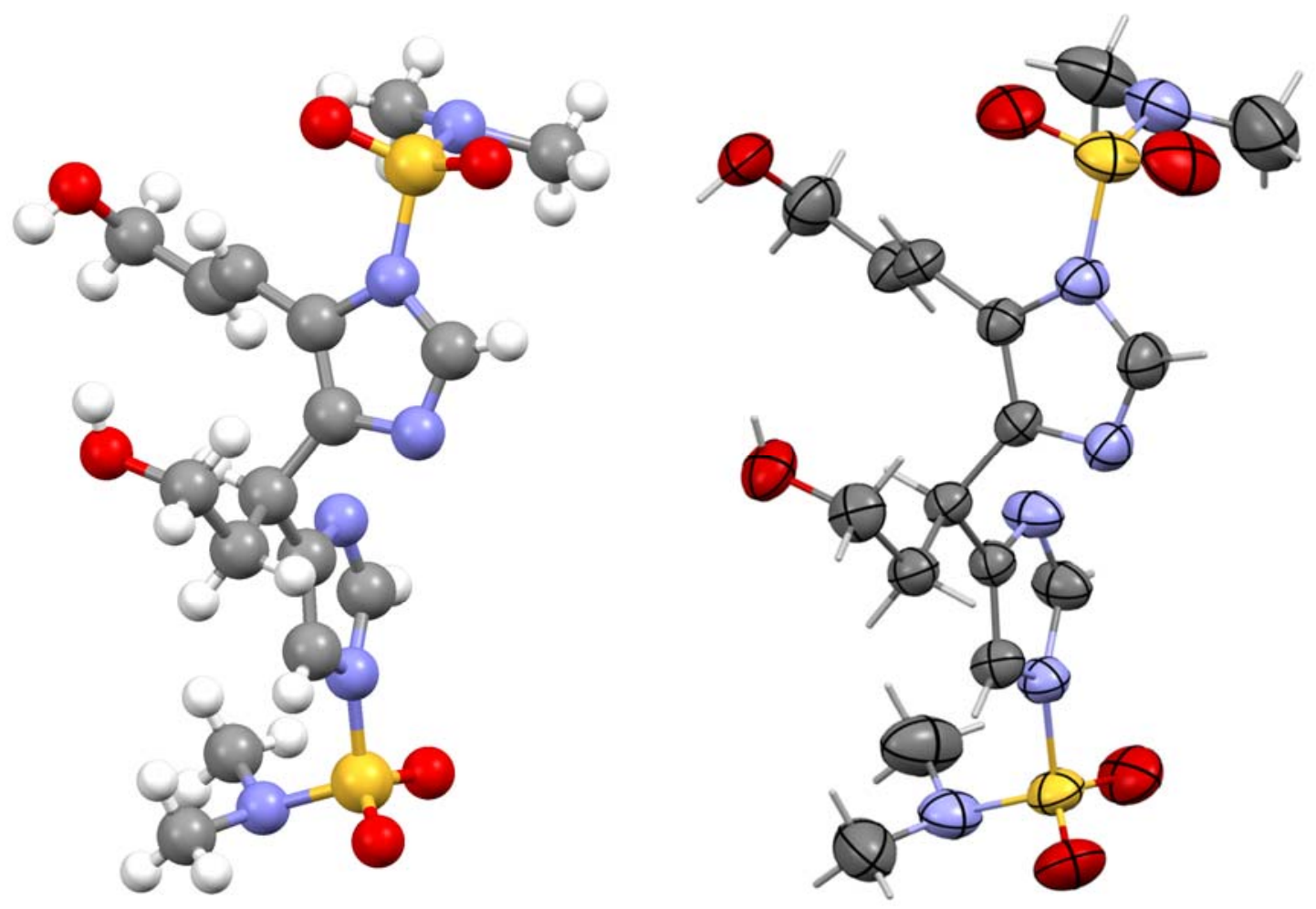

Figure S1: X-ray plots of compound $\mathbf{6 1}$ (ORTEP right at 50\% probability) 
Table 1. Crystal data and structure refinement for C16 H26 N6 O6 S2 (Compound 61)

Identification code

Empirical formula

Formula weight

Temperature

Wavelength

Crystal system

Space group

Unit cell dimensions

Volume

Z

Density (calculated)

Absorption coefficient

$\mathrm{F}(000)$

Crystal size

Theta range for data collection

Index ranges

Reflections collected

Independent reflections

Completeness to theta $=28.34^{\circ}$

Absorption correction

Refinement method

Data / restraints / parameters

Goodness-of-fit on $\mathrm{F}^{2}$

Final R indices [I $>2 \operatorname{sigma(I)]~}$

$\mathrm{R}$ indices (all data)

Largest diff. peak and hole manoj17m

C16 H26 N6 O6 S2

462.55

296(2) K

$0.71073 \AA$

Monoclinic

$\mathrm{P} 2(1) / \mathrm{c}$

$\mathrm{a}=25.703(4) \AA$

$\alpha=90^{\circ}$.

$\mathrm{b}=7.1957(12) \AA$

$\beta=99.356(2)^{\circ}$.

$\mathrm{c}=12.219(2) \AA$

$\gamma=90^{\circ}$.
2229.9(6) $\AA^{3}$

4

$1.378 \mathrm{Mg} / \mathrm{m}^{3}$

$0.283 \mathrm{~mm}^{-1}$

976

$0.29 \times 0.20 \times 0.08 \mathrm{~mm}^{3}$

1.61 to $28.34^{\circ}$.

$-34<=\mathrm{h}<=34,-9<=\mathrm{k}<=9,-16<=\mathrm{l}<=16$

21123

5549 [R(int) $=0.0495]$

$99.5 \%$

None

Full-matrix least-squares on $\mathrm{F}^{2}$

5549 / 0 / 277

1.036

$\mathrm{R} 1=0.0440, \mathrm{wR} 2=0.1041$

$\mathrm{R} 1=0.0676, \mathrm{wR} 2=0.1109$

0.355 and -0.191 e. $\AA^{-3}$ 

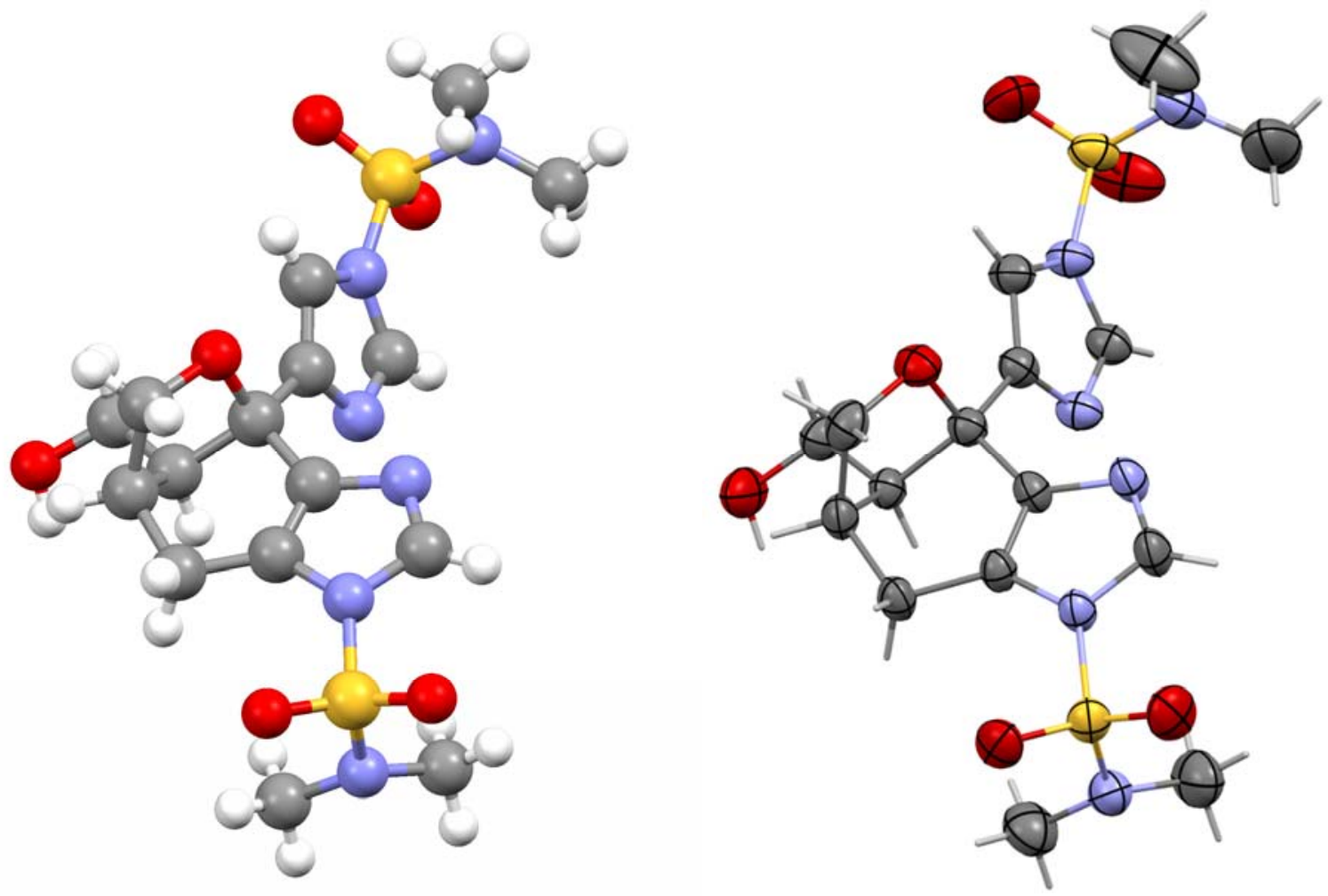

Figure S2: X-ray plots of compound 62 (ORTEP right at 50\% probability) 
Table 2. Crystal data and structure refinement for C16 H26 N6 O6 S2 (Compound 62).

Identification code

Empirical formula

Formula weight

Temperature

Wavelength

Crystal system

Space group

Unit cell dimensions

Volume

Z

Density (calculated)

Absorption coefficient

$\mathrm{F}(000)$

Crystal size

Theta range for data collection

Index ranges

Reflections collected

Independent reflections

Completeness to theta $=28.34^{\circ}$

Absorption correction

Refinement method

Data / restraints / parameters

Goodness-of-fit on $\mathrm{F}^{2}$

Final $\mathrm{R}$ indices [I $>2 \operatorname{sigma}(\mathrm{I})]$

$\mathrm{R}$ indices (all data)

Largest diff. peak and hole manoj17m

C16 H26 N6 O6 S2

462.55

296(2) K

$0.71073 \AA$

Monoclinic

$\mathrm{P} 2(1) / \mathrm{c}$

$\mathrm{a}=25.703(4) \AA$

$\alpha=90^{\circ}$.

$\mathrm{b}=7.1957(12) \AA$

$\beta=99.356(2)^{\circ}$.

$\mathrm{c}=12.219(2) \AA$

$\gamma=90^{\circ}$.

2229.9(6) $\AA^{3}$

4

$1.378 \mathrm{Mg} / \mathrm{m}^{3}$

$0.283 \mathrm{~mm}^{-1}$

976

$0.29 \times 0.20 \times 0.08 \mathrm{~mm}^{3}$

1.61 to $28.34^{\circ}$.

$-34<=\mathrm{h}<=34,-9<=\mathrm{k}<=9,-16<=\mathrm{l}<=16$

21123

5549 [R(int) $=0.0495]$

$99.5 \%$

None

Full-matrix least-squares on $\mathrm{F}^{2}$

5549 / 0 / 277

1.036

$\mathrm{R} 1=0.0440, \mathrm{wR} 2=0.1041$

$\mathrm{R} 1=0.0676, \mathrm{wR} 2=0.1109$

0.355 and -0.191 e. $\AA^{-3}$ 


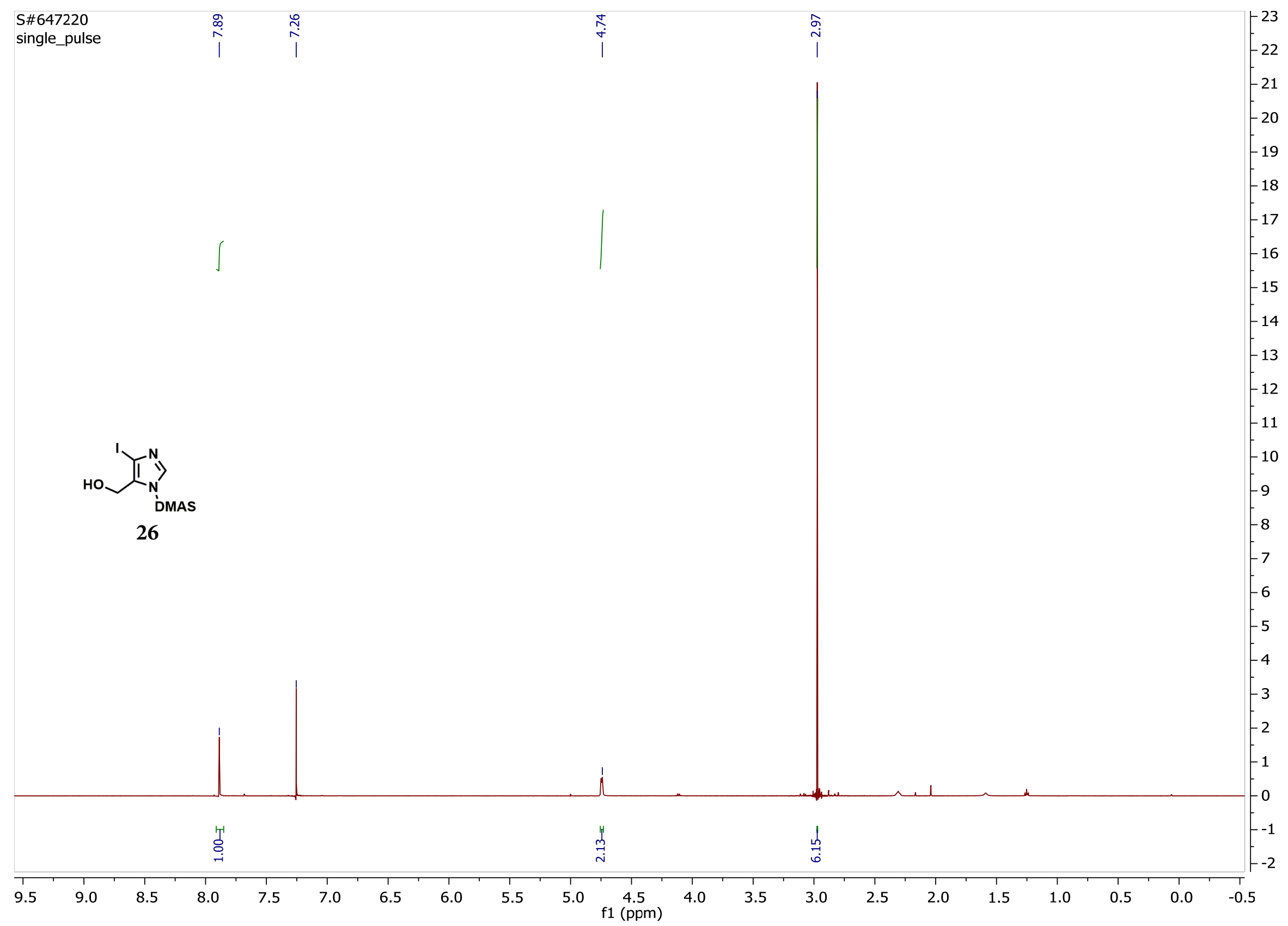




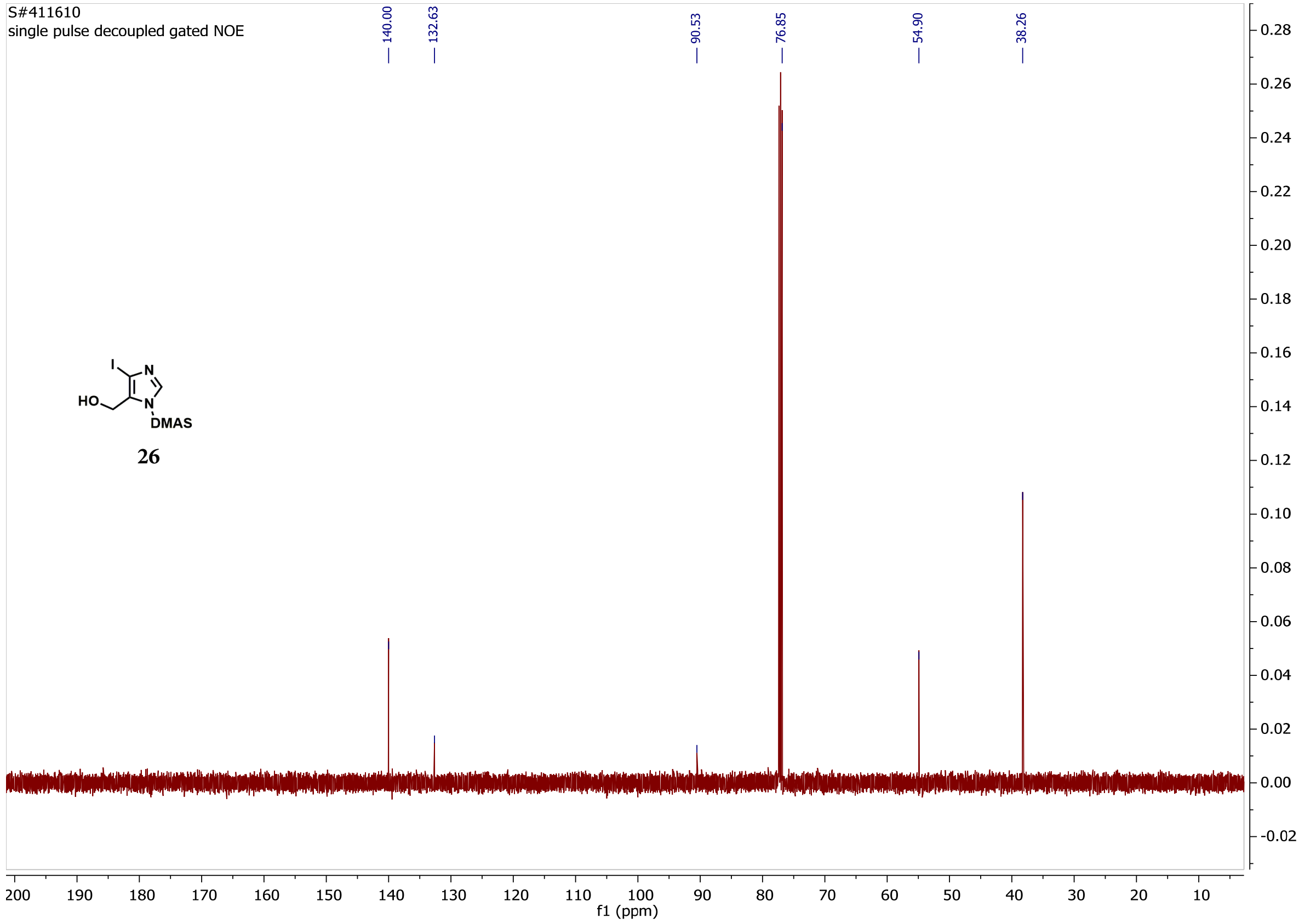




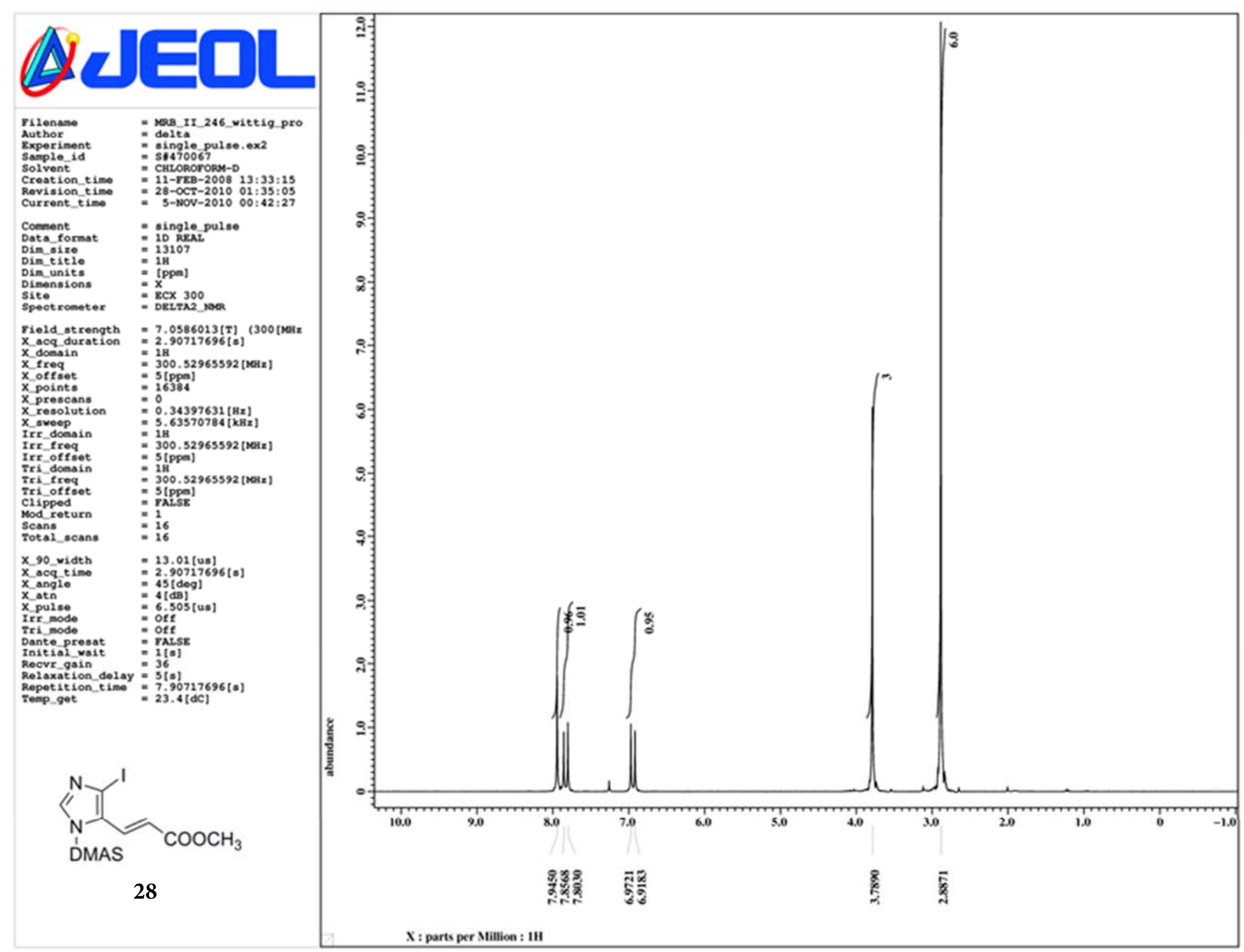




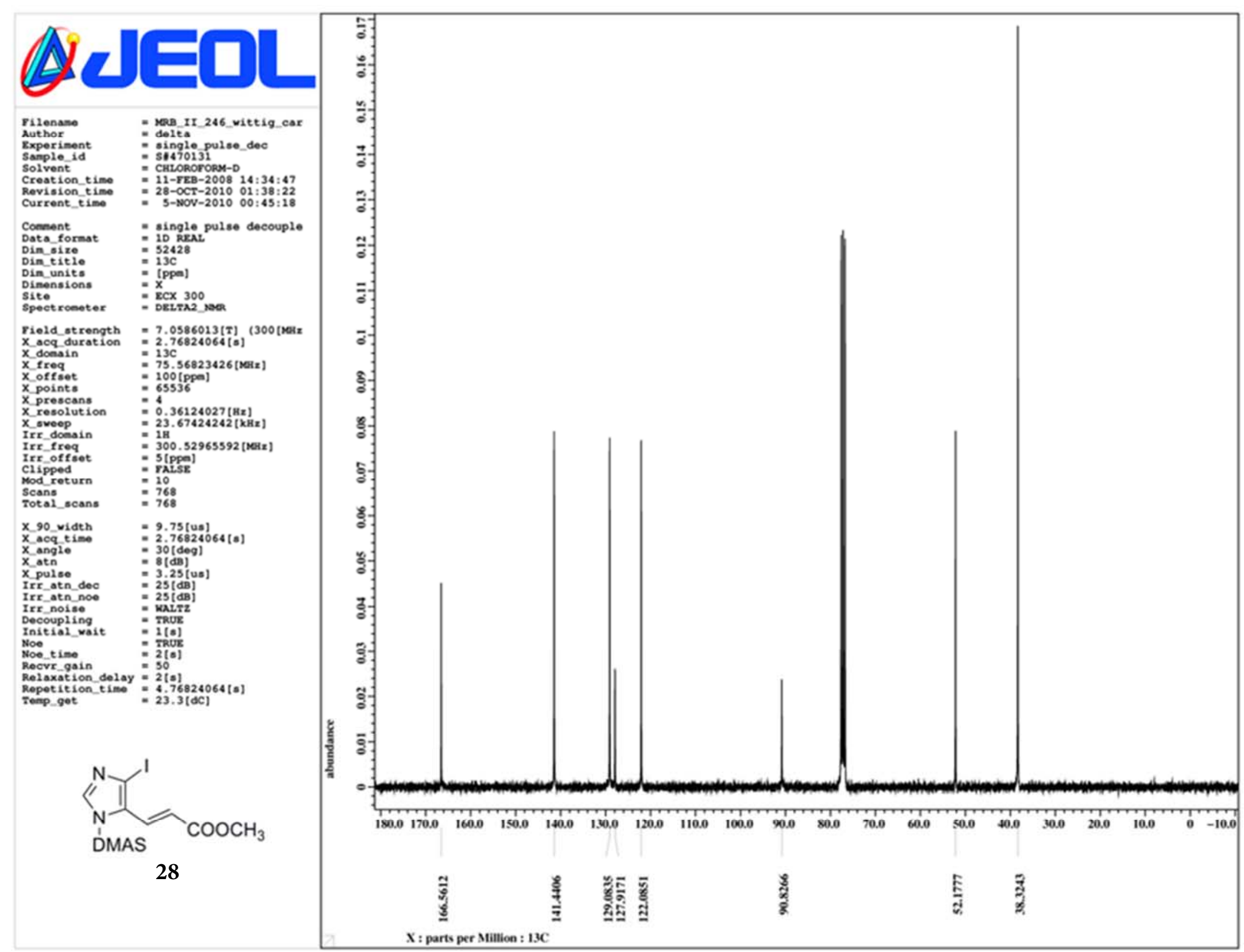




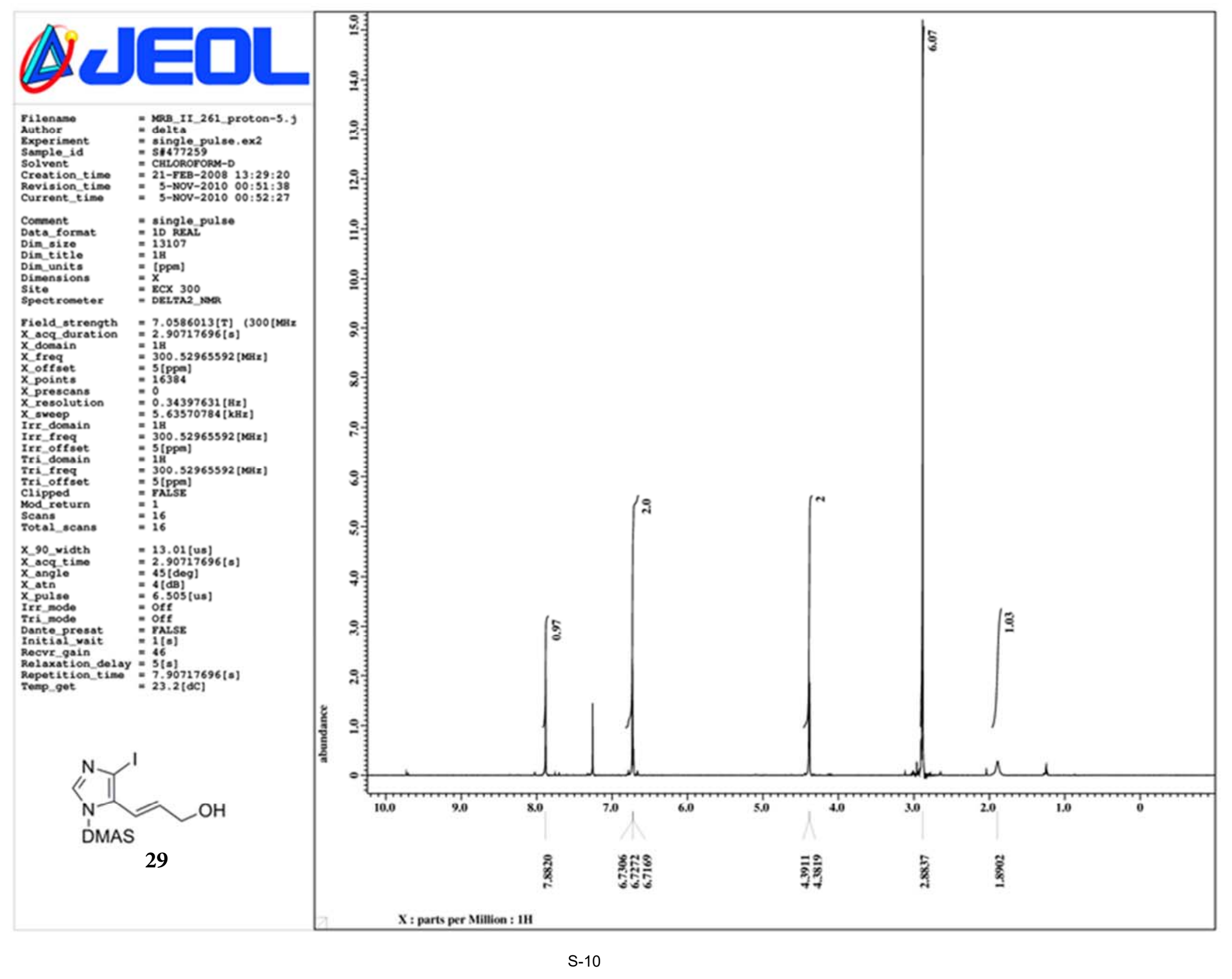




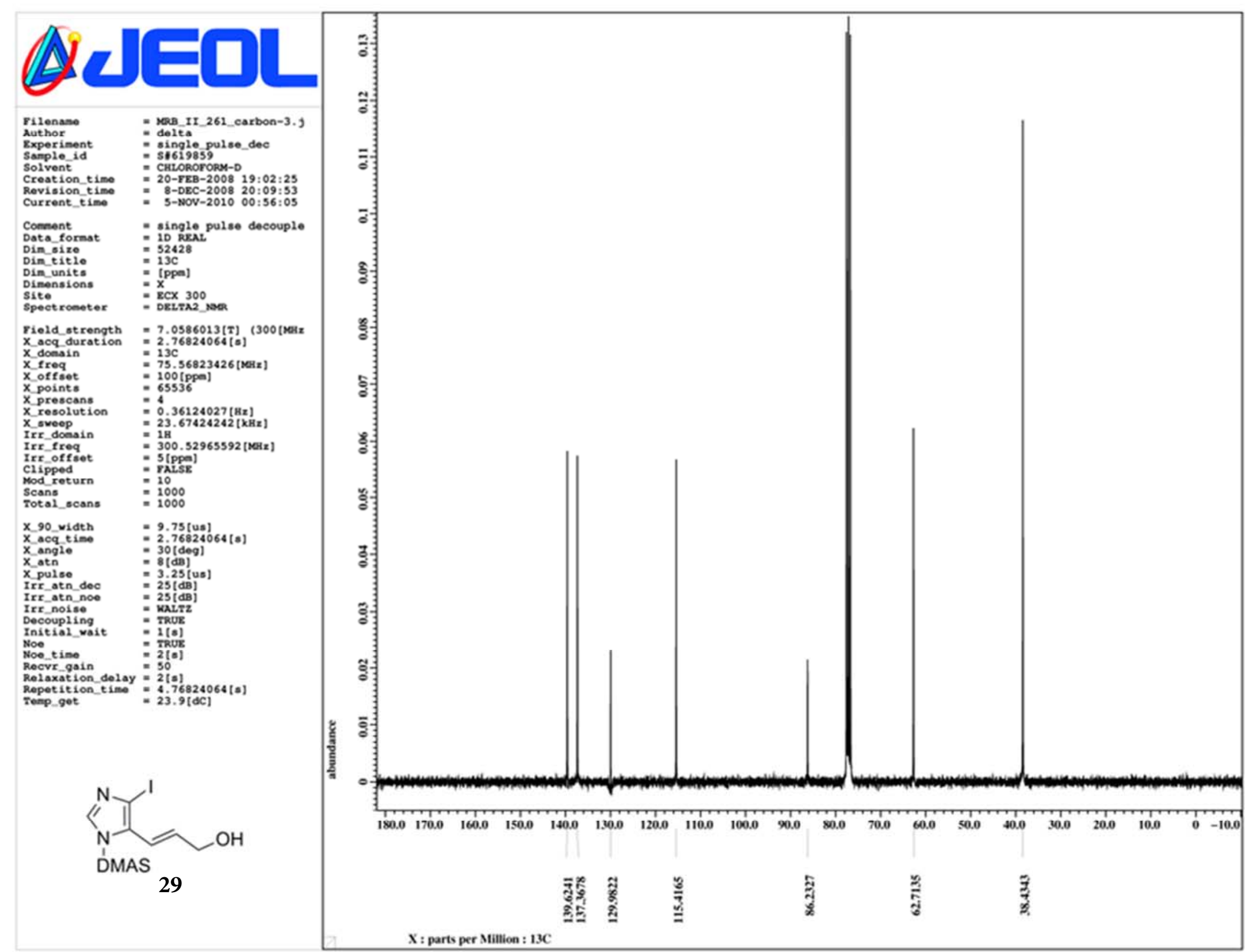




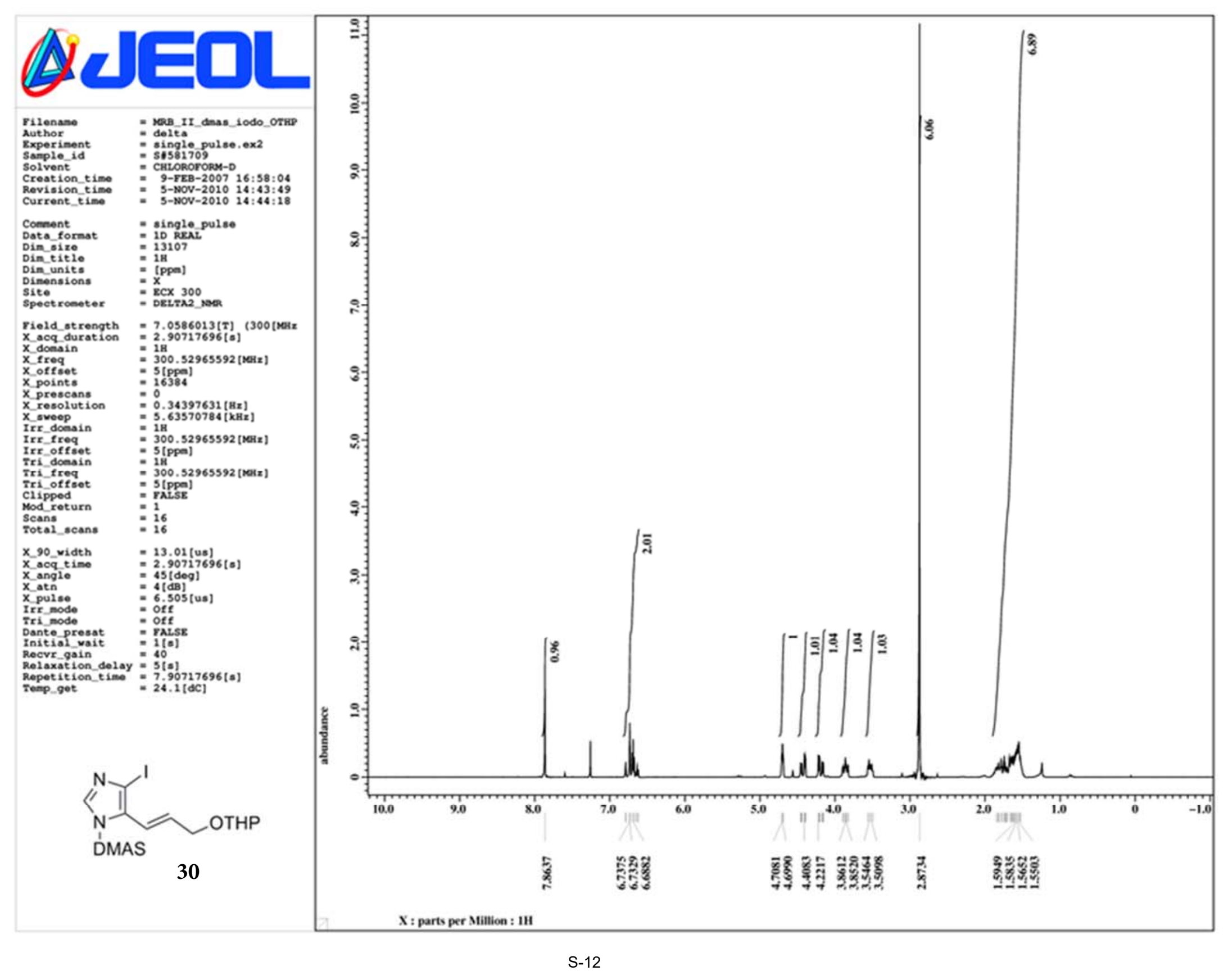




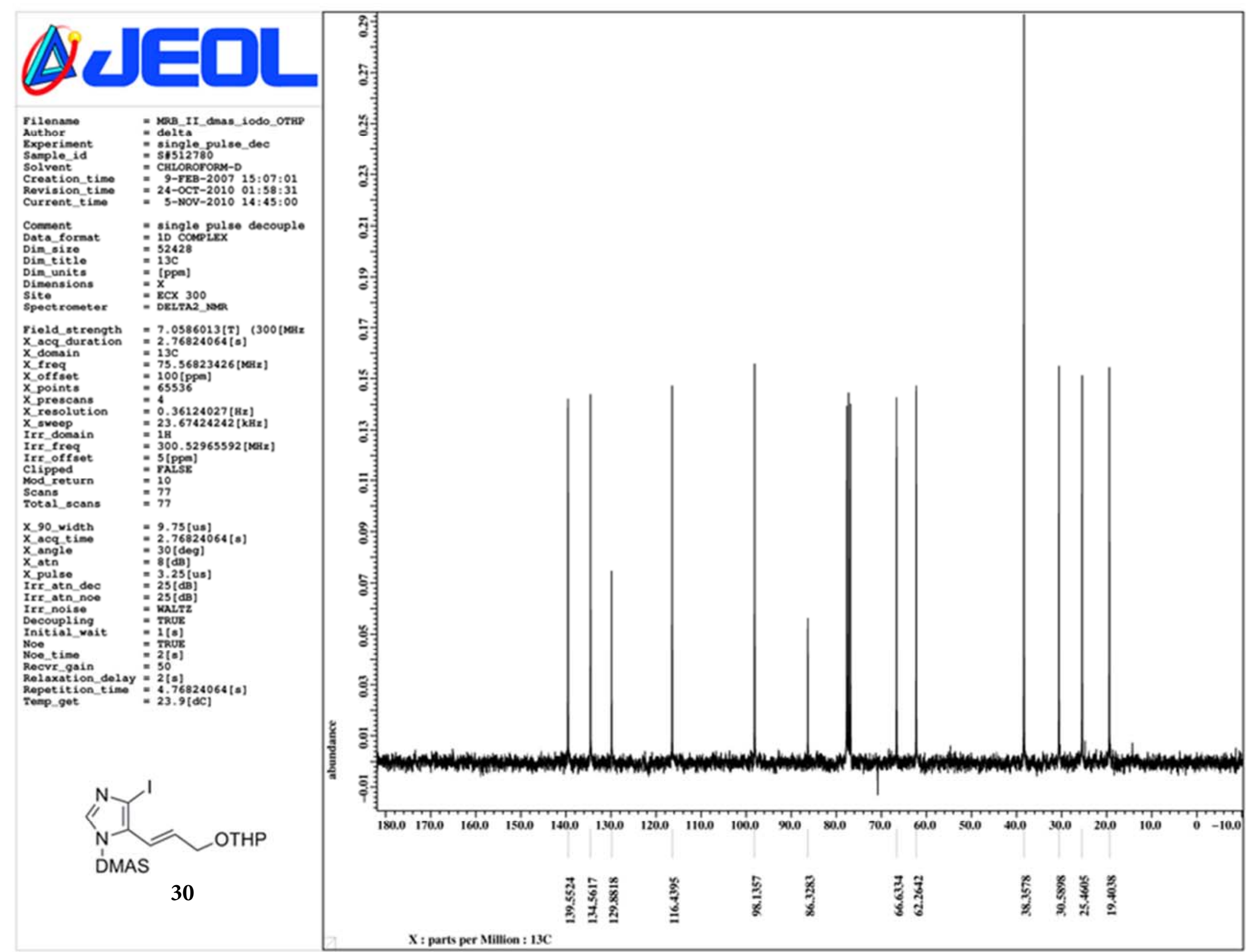




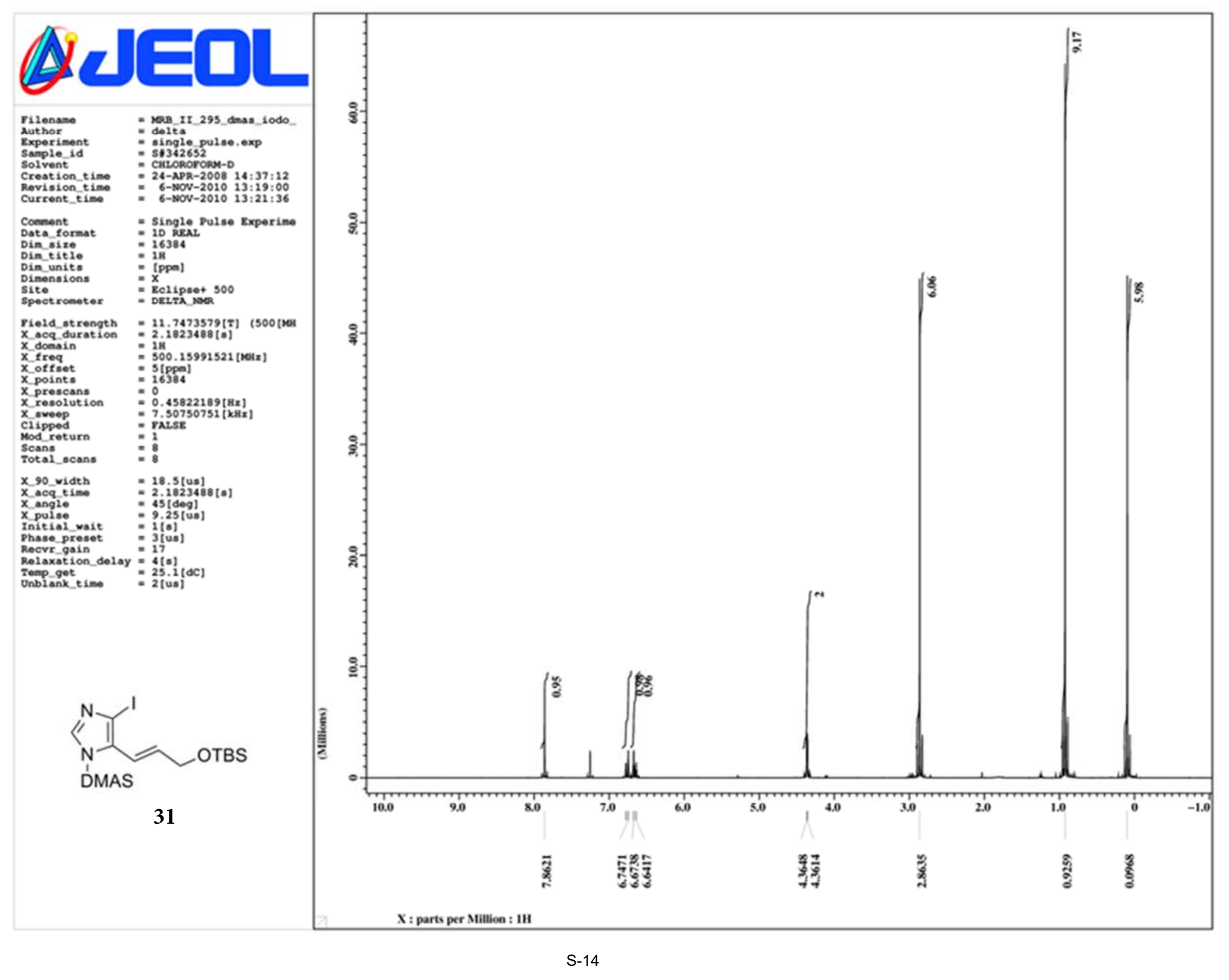




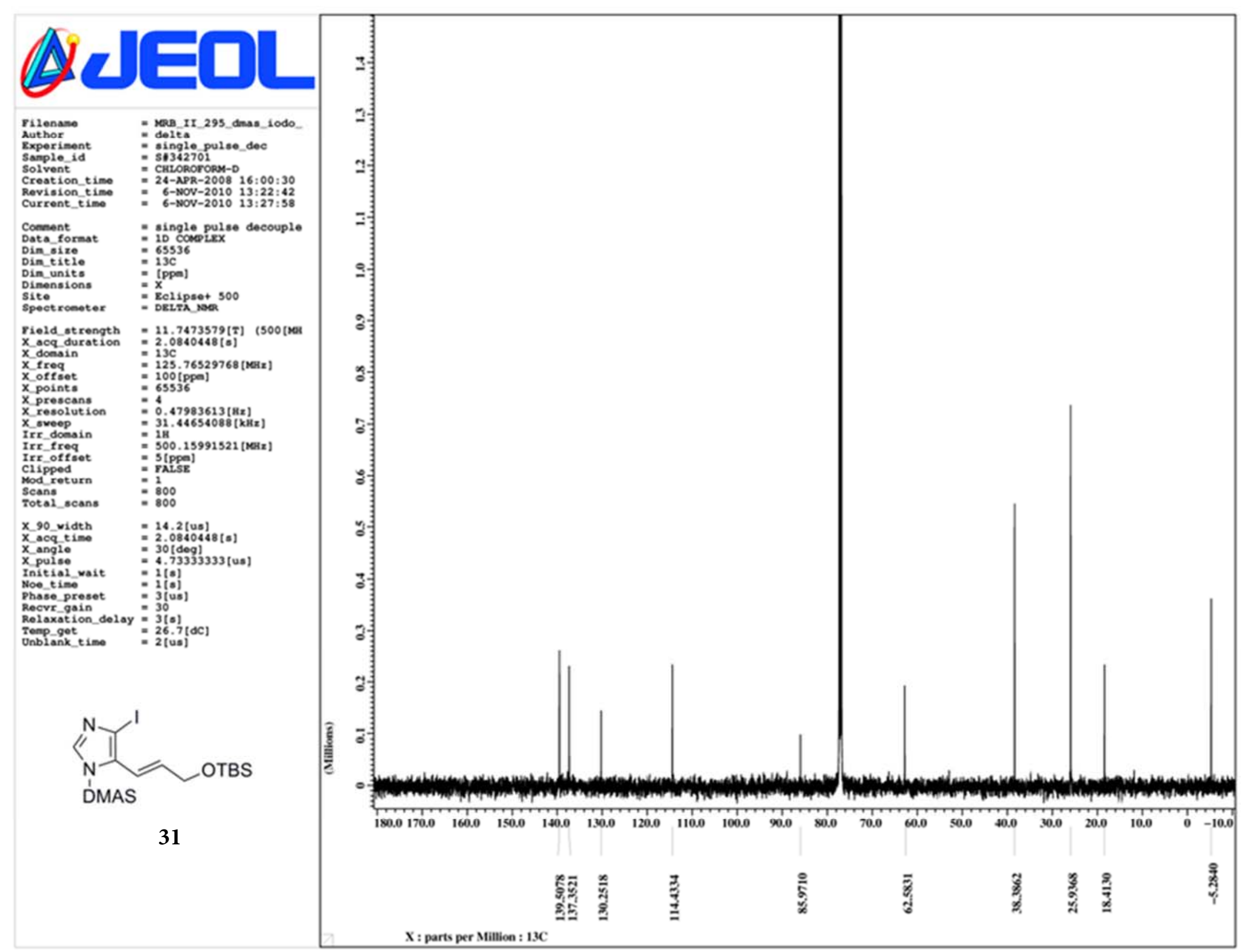




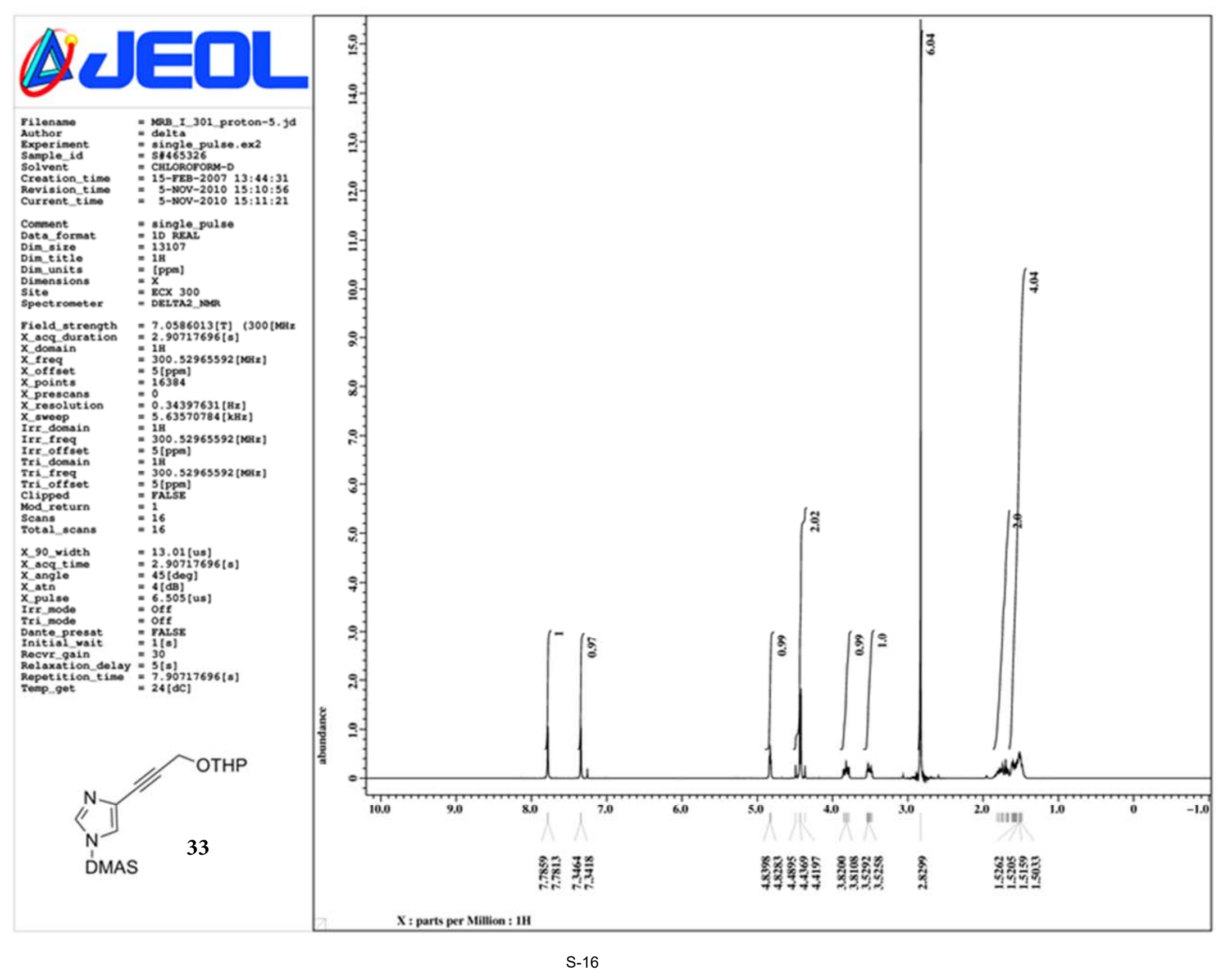




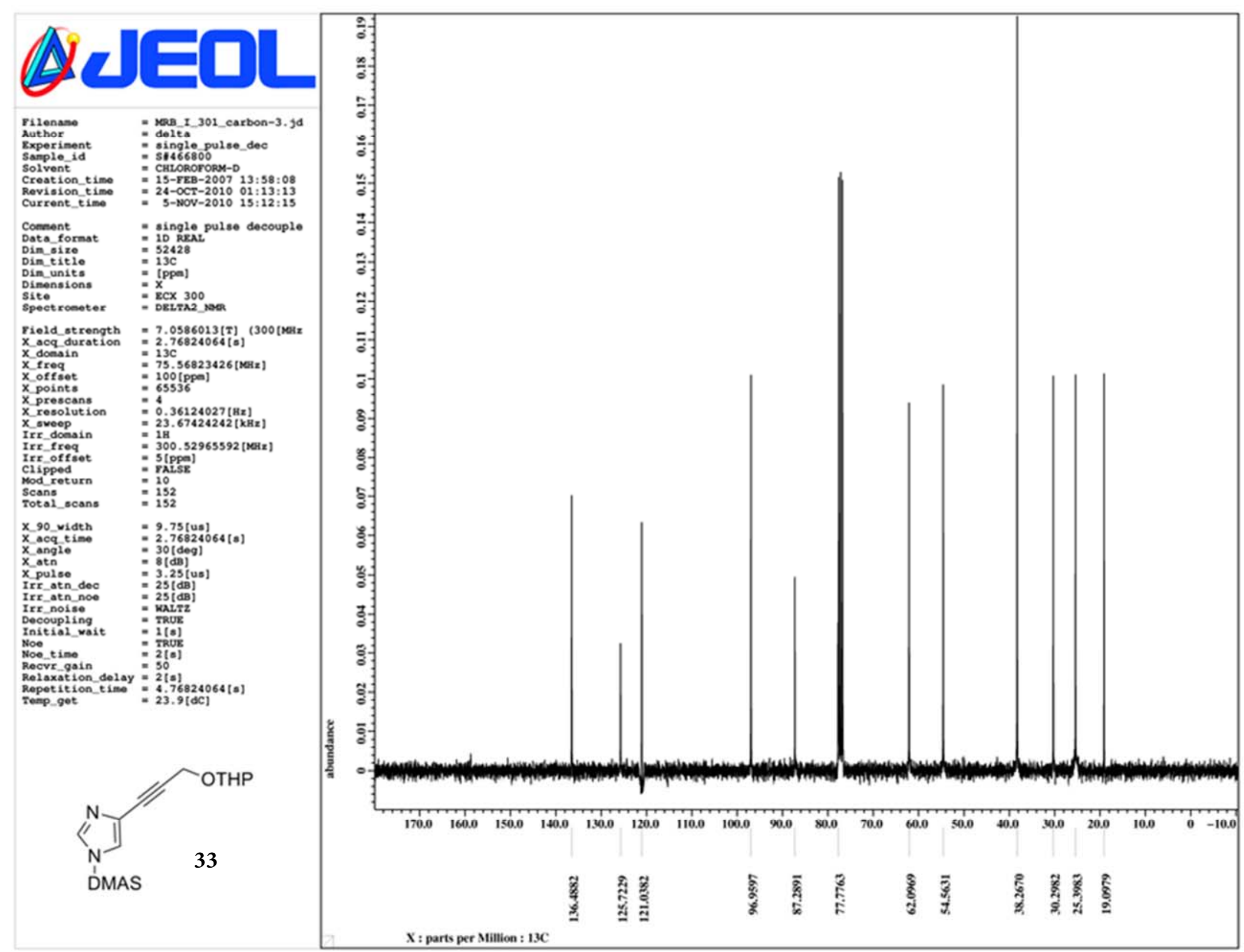




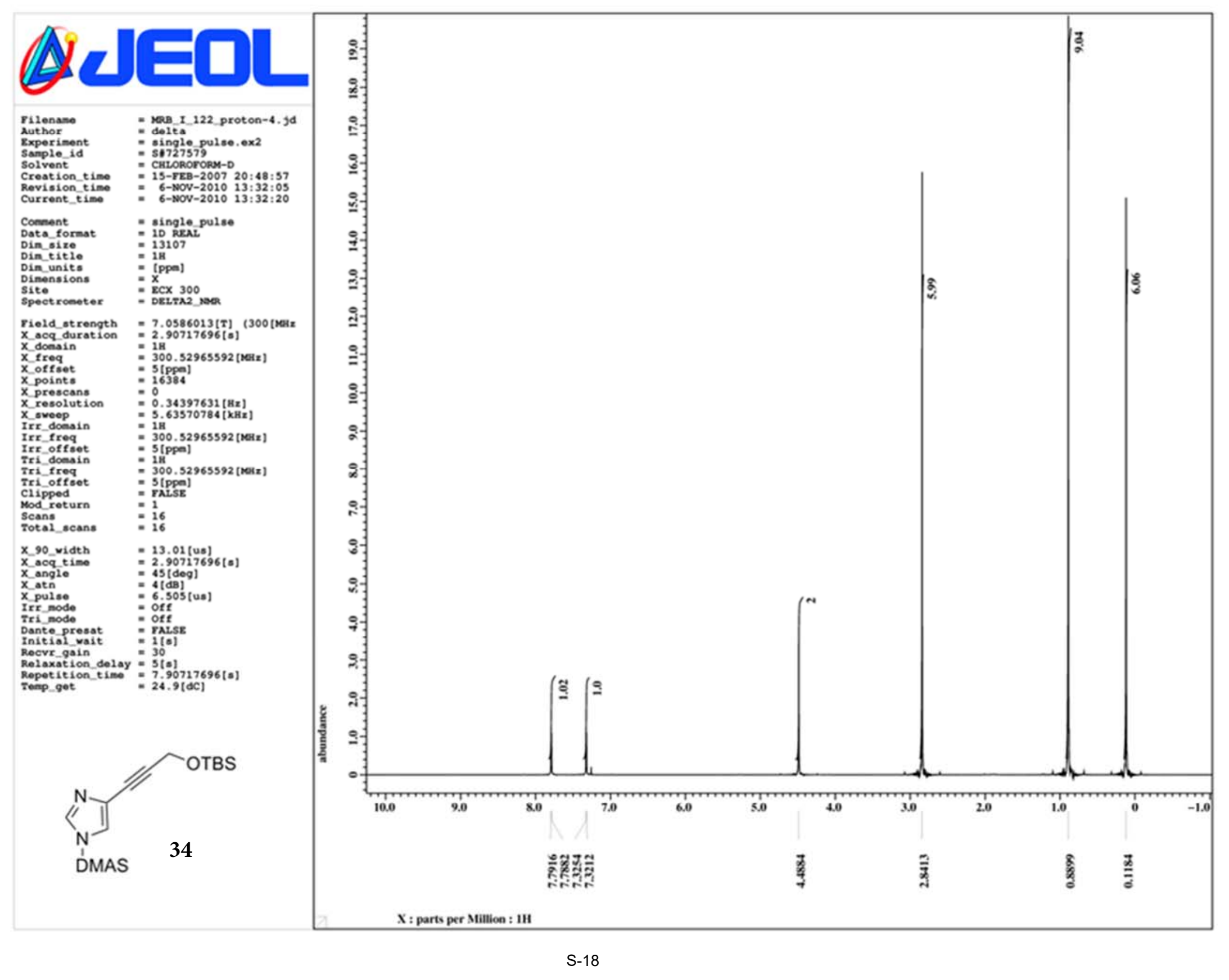




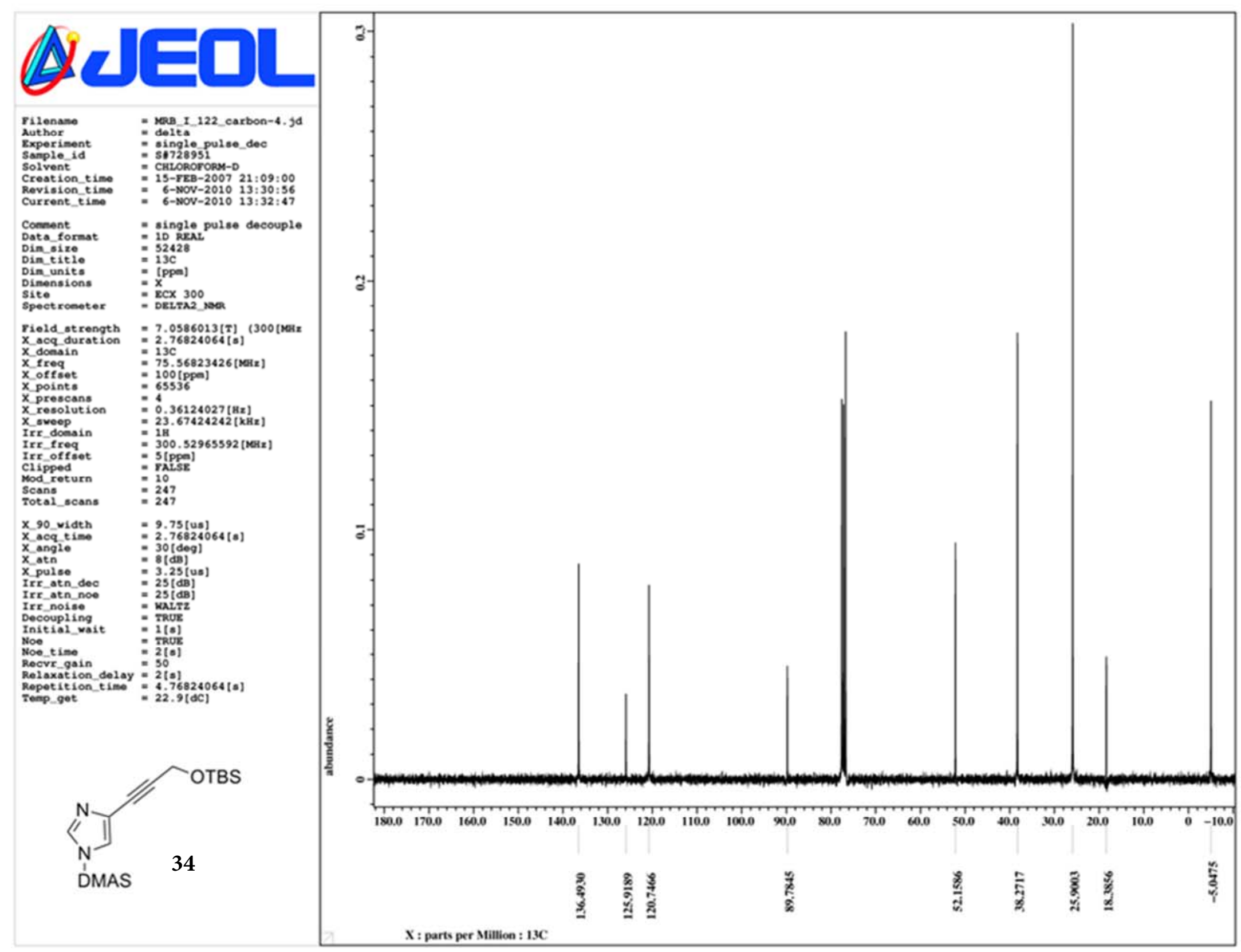




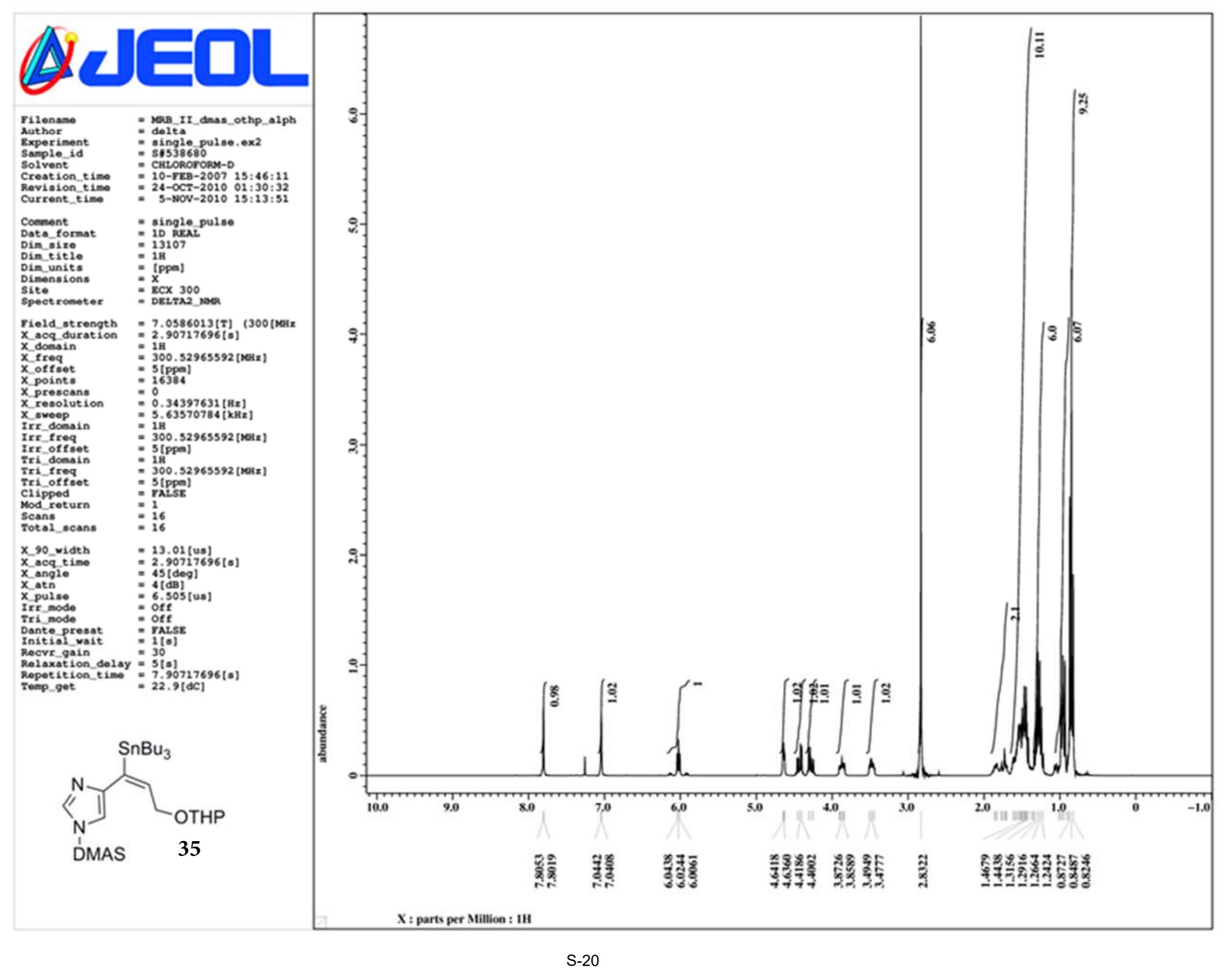




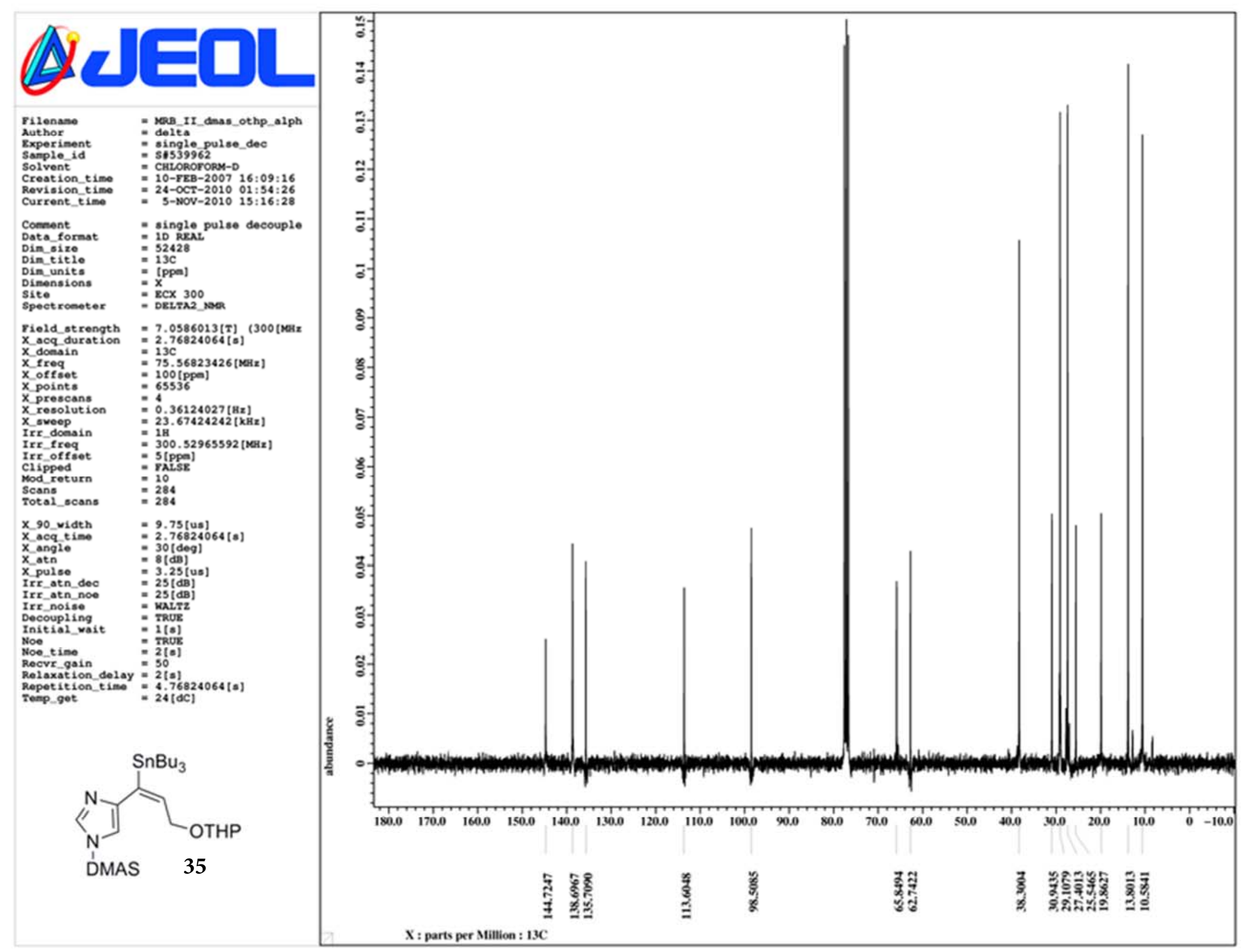




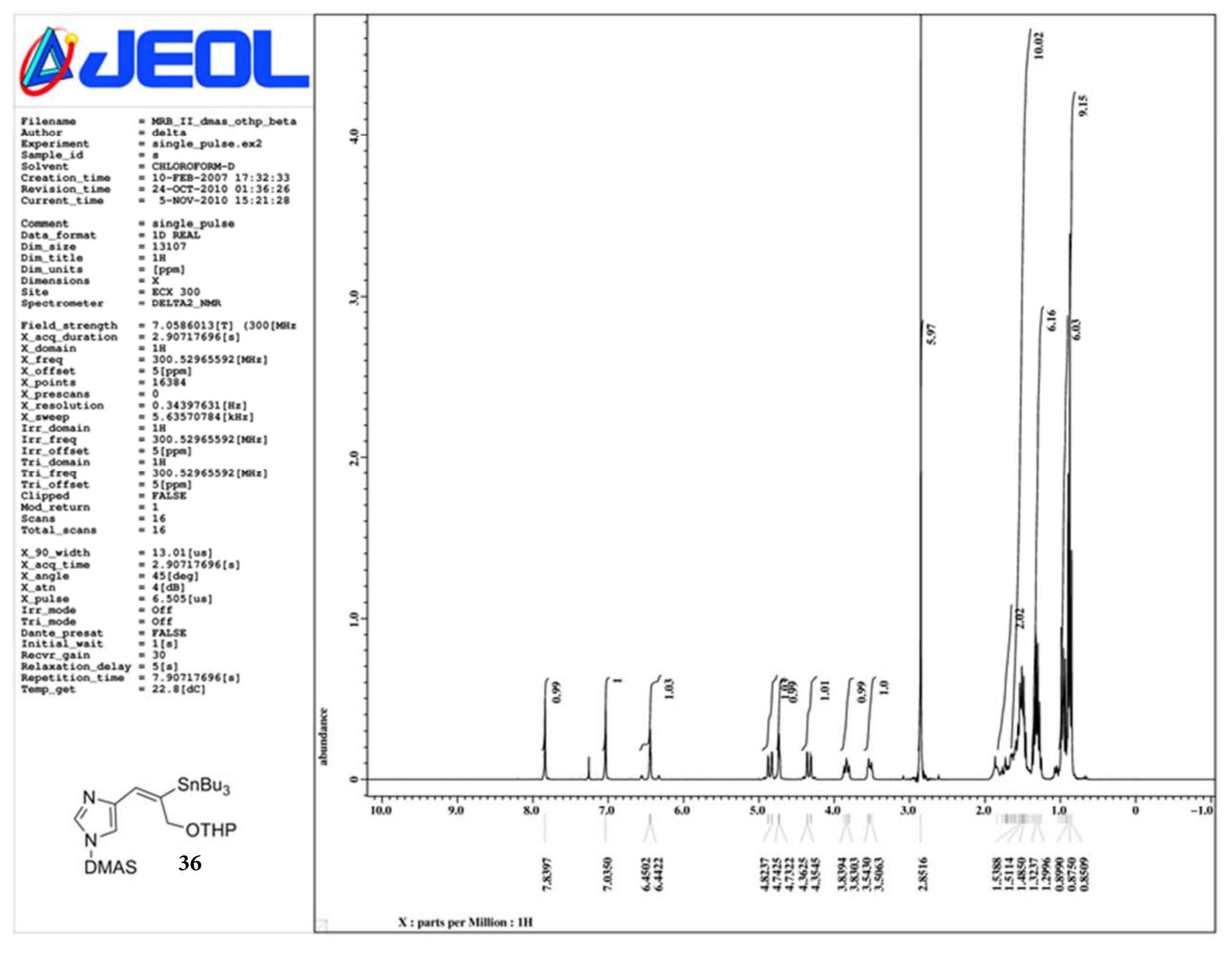




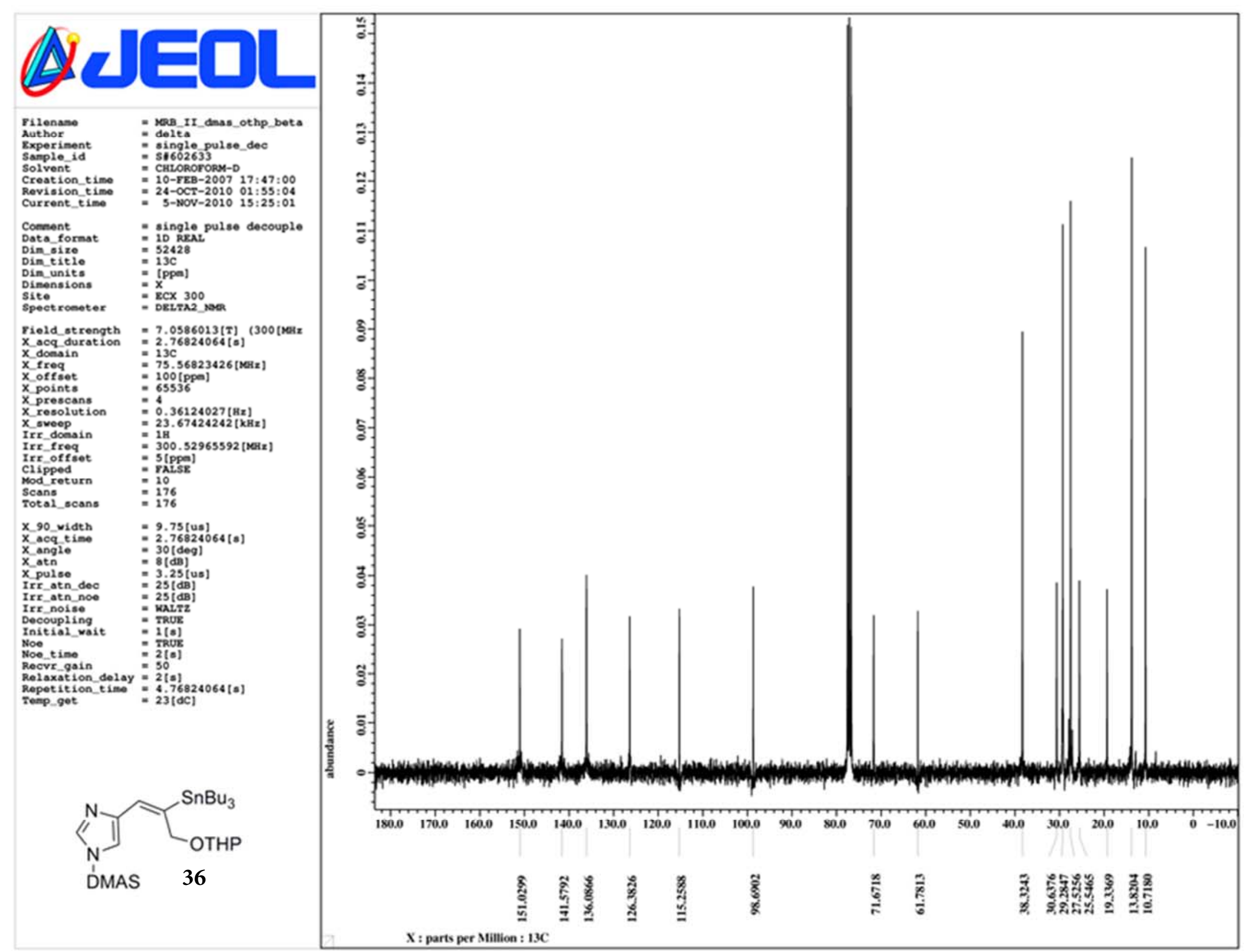




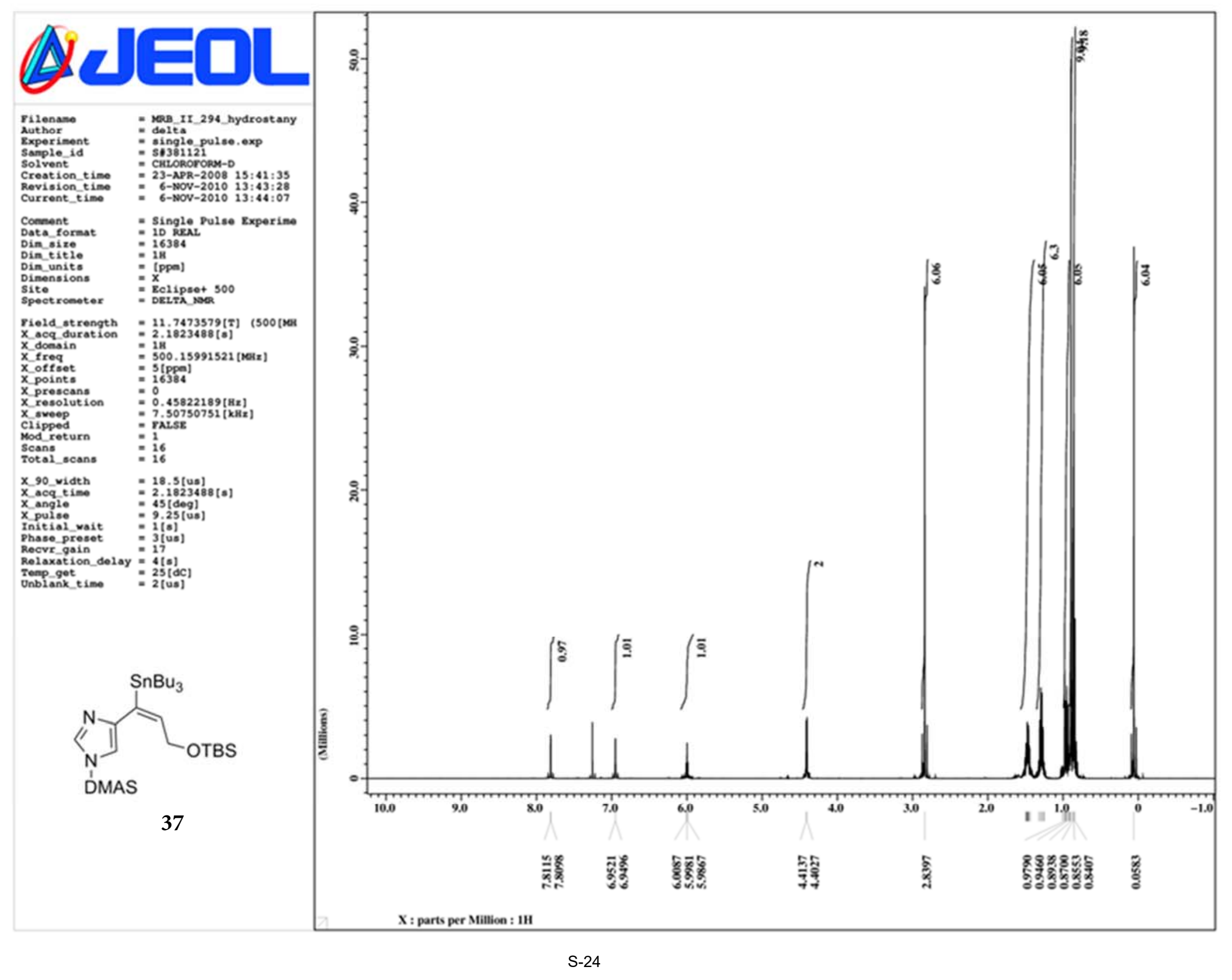




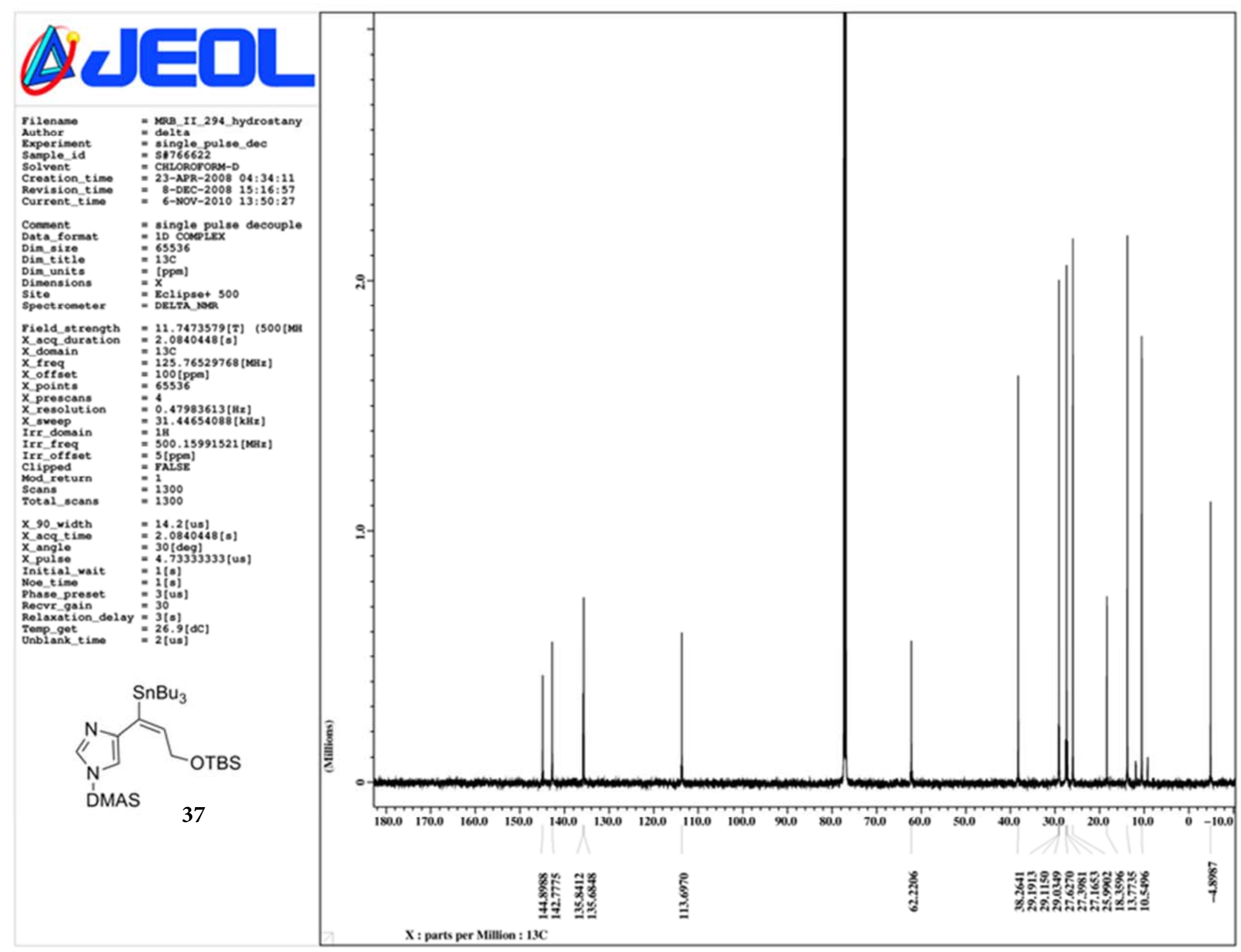




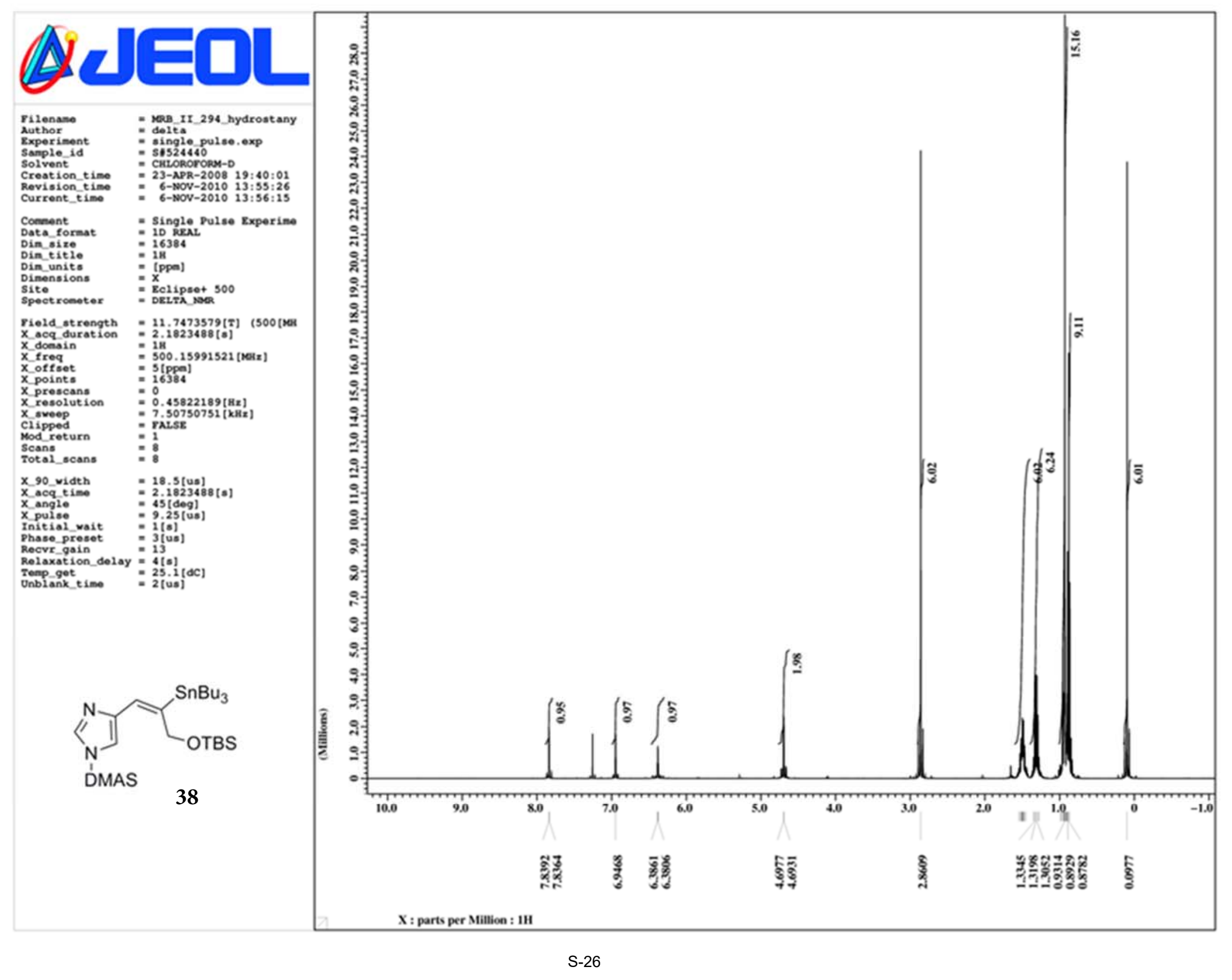




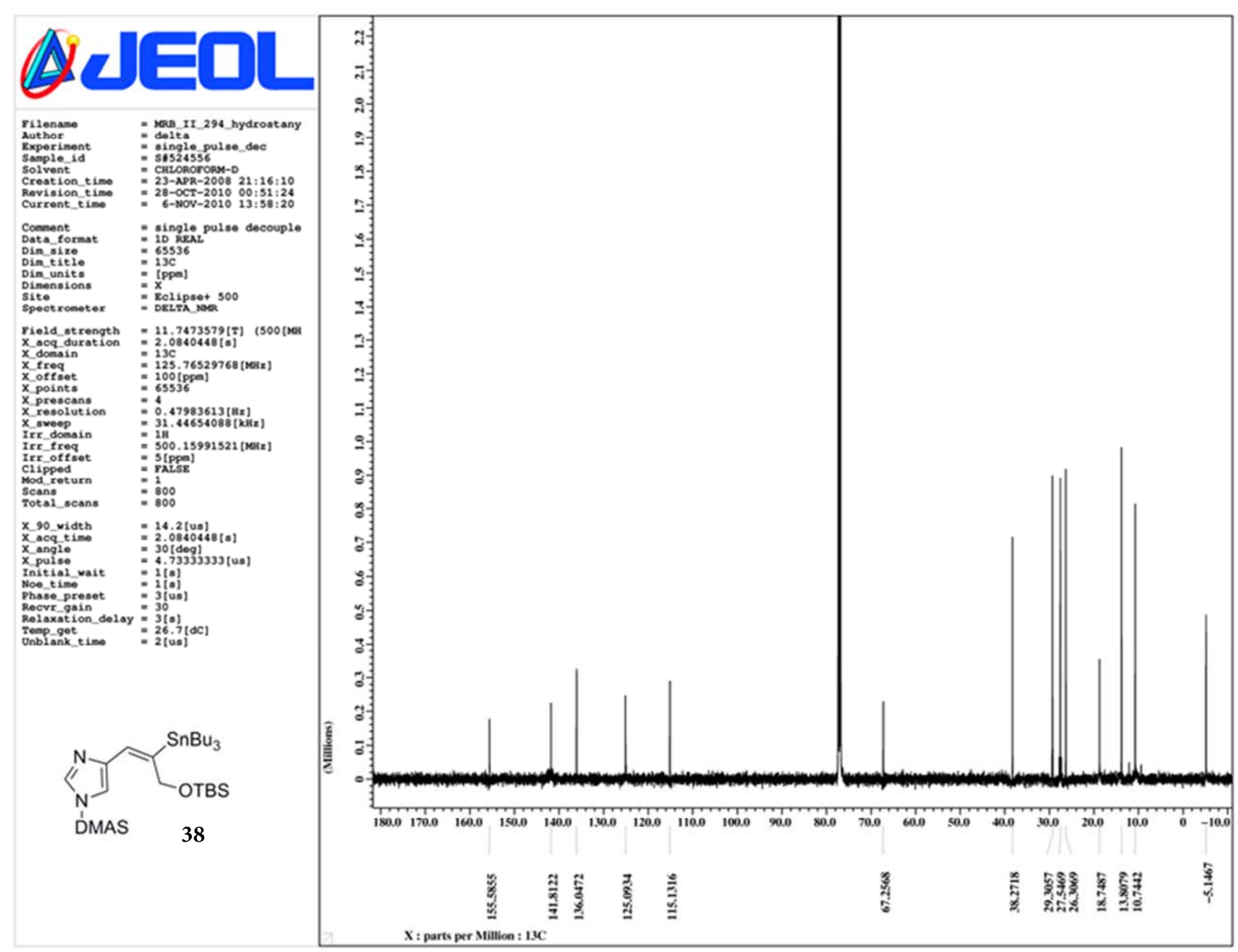




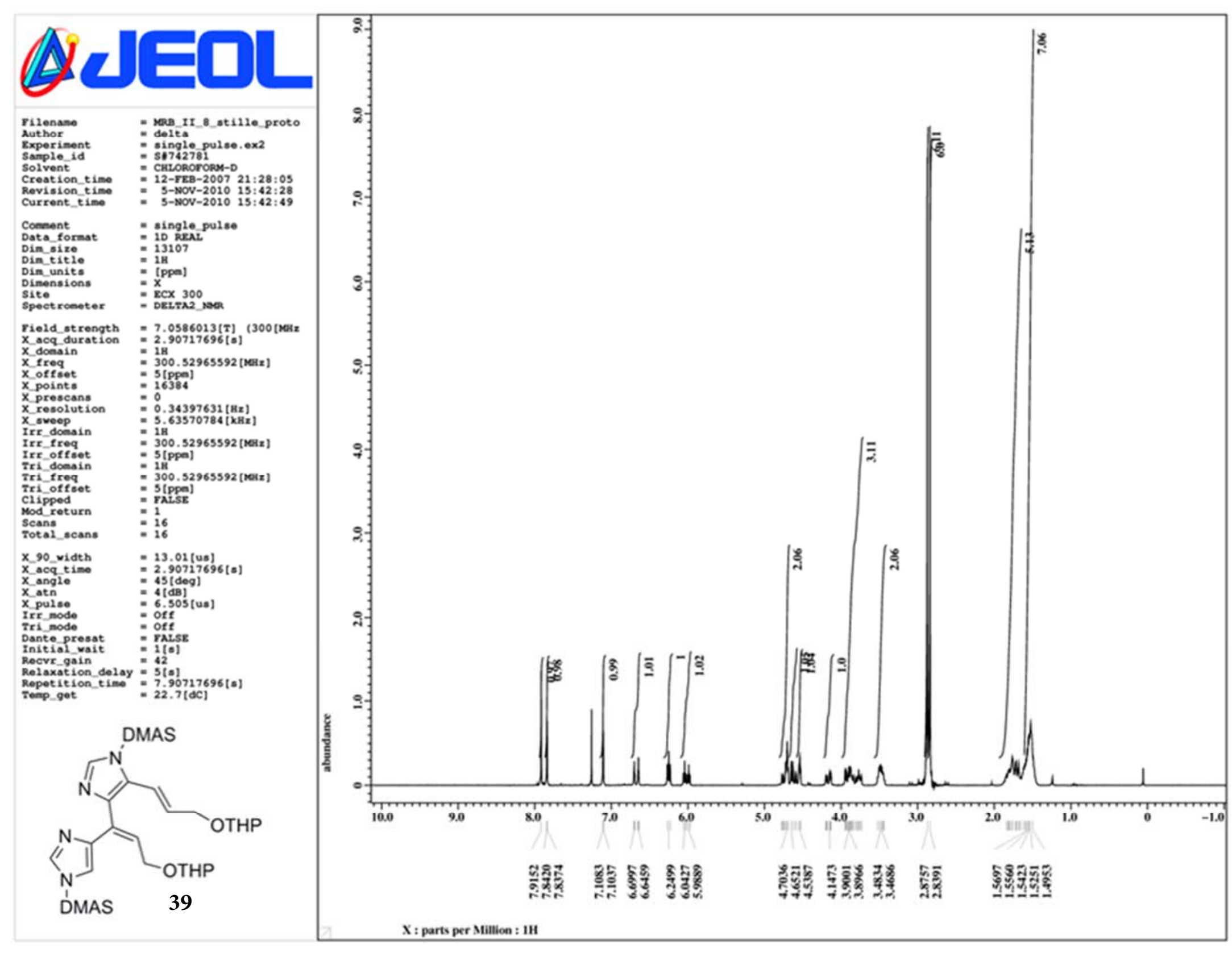




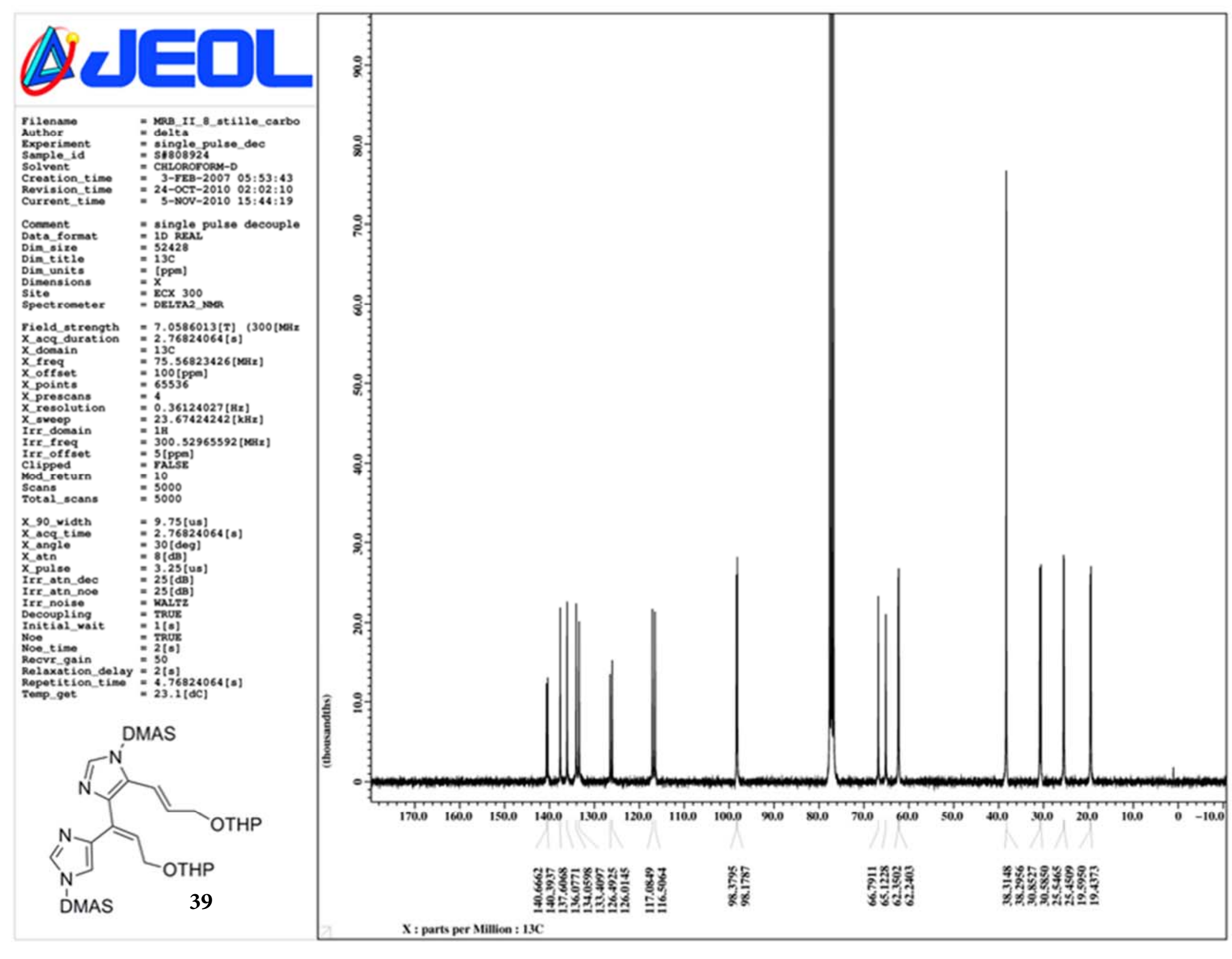




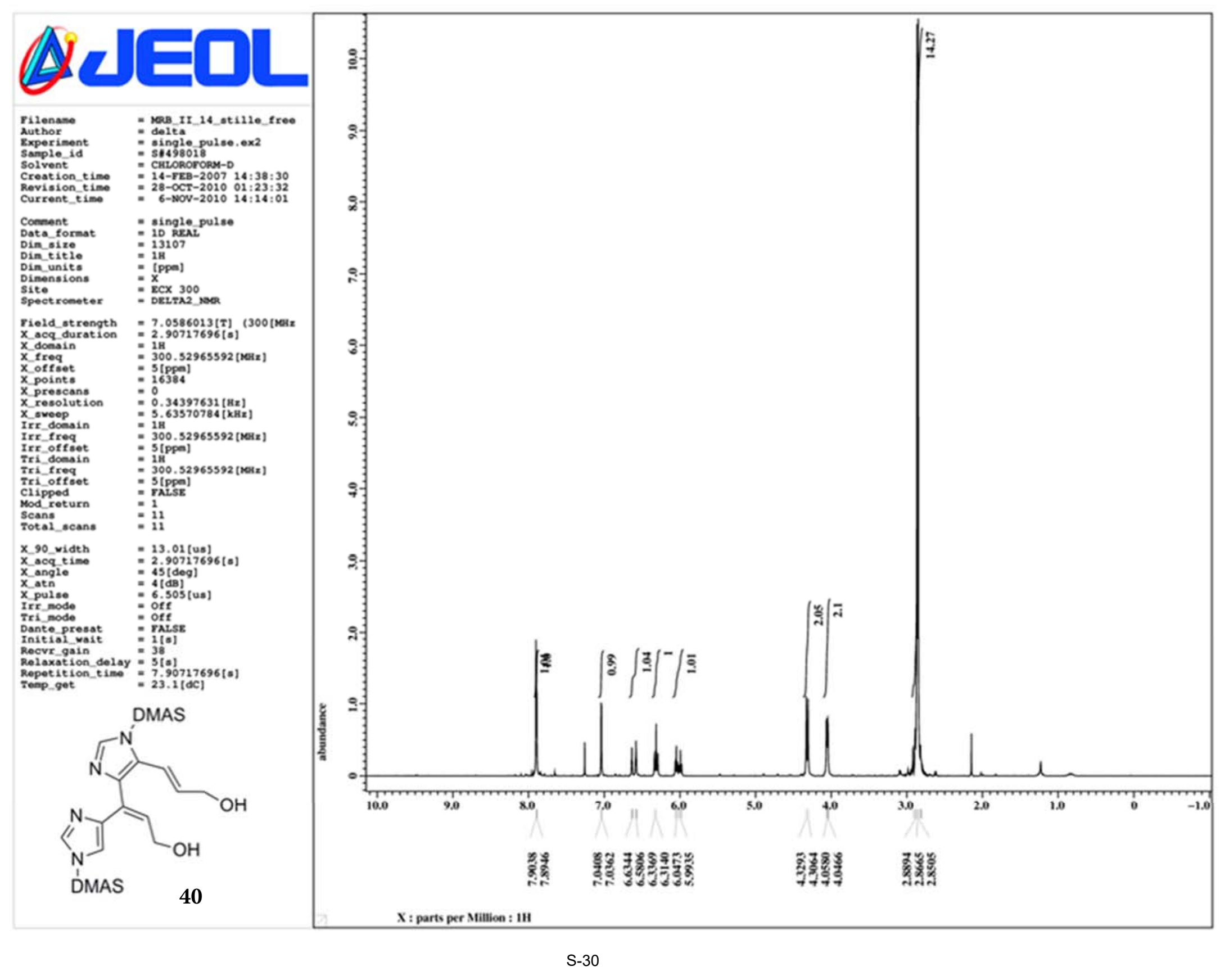




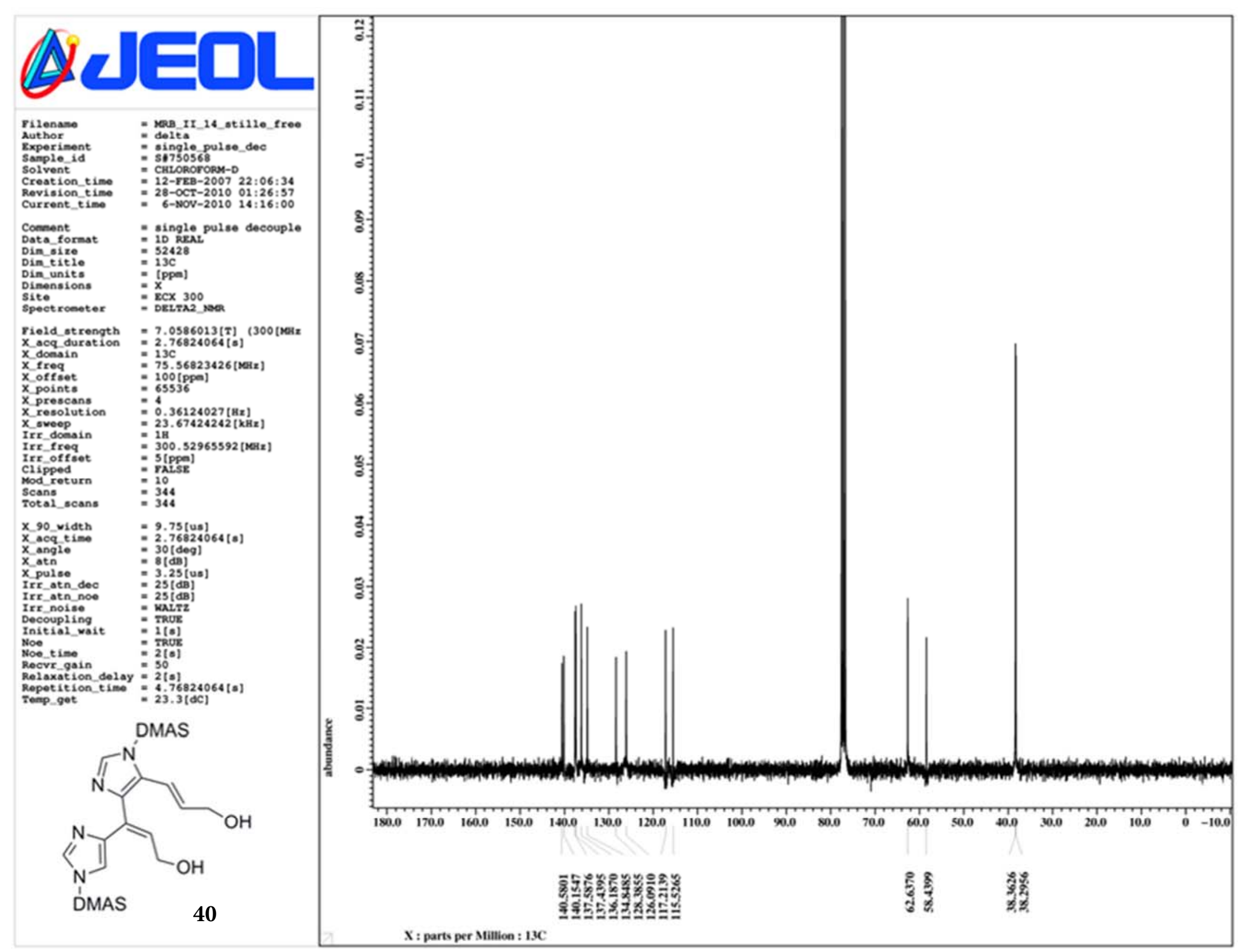




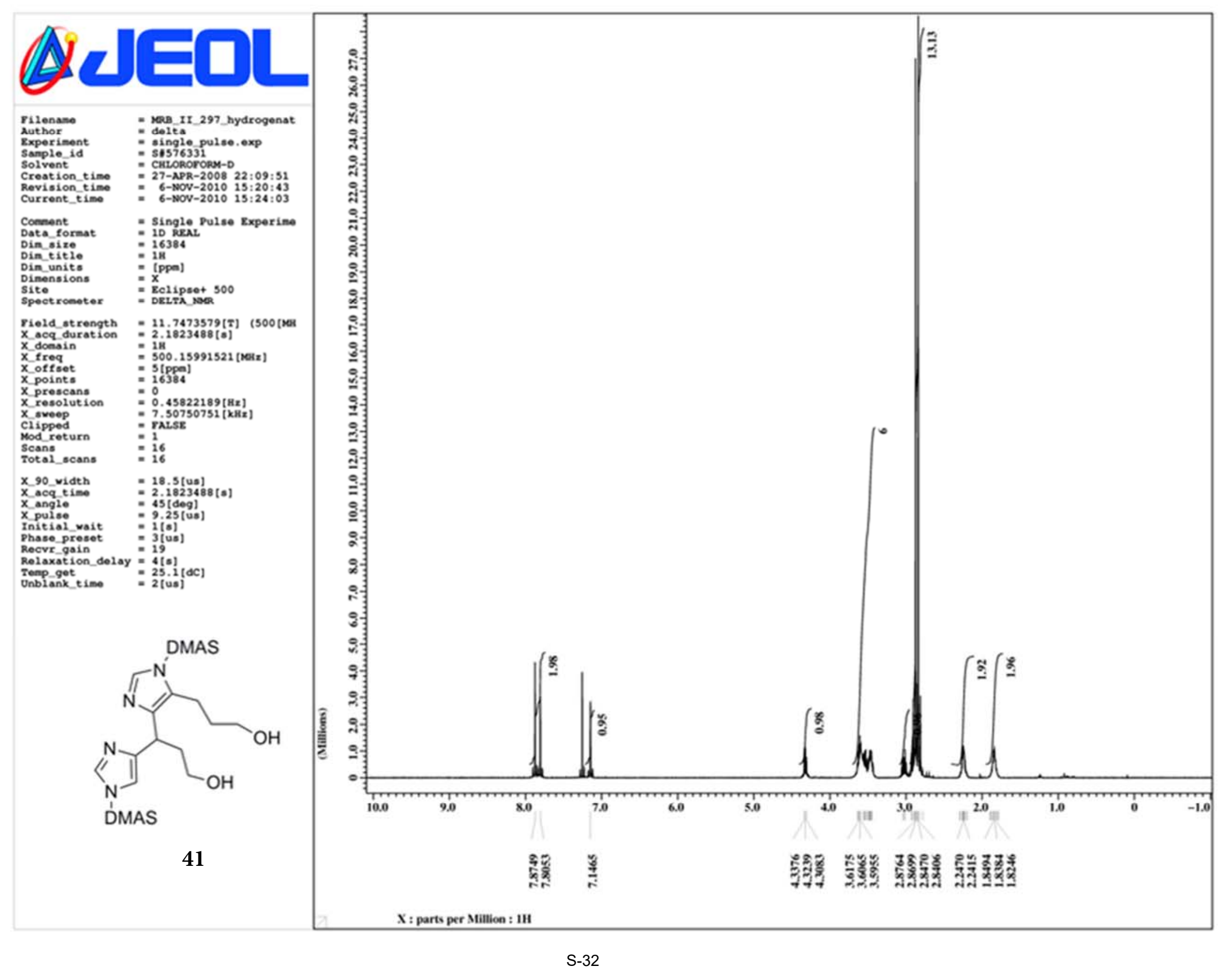




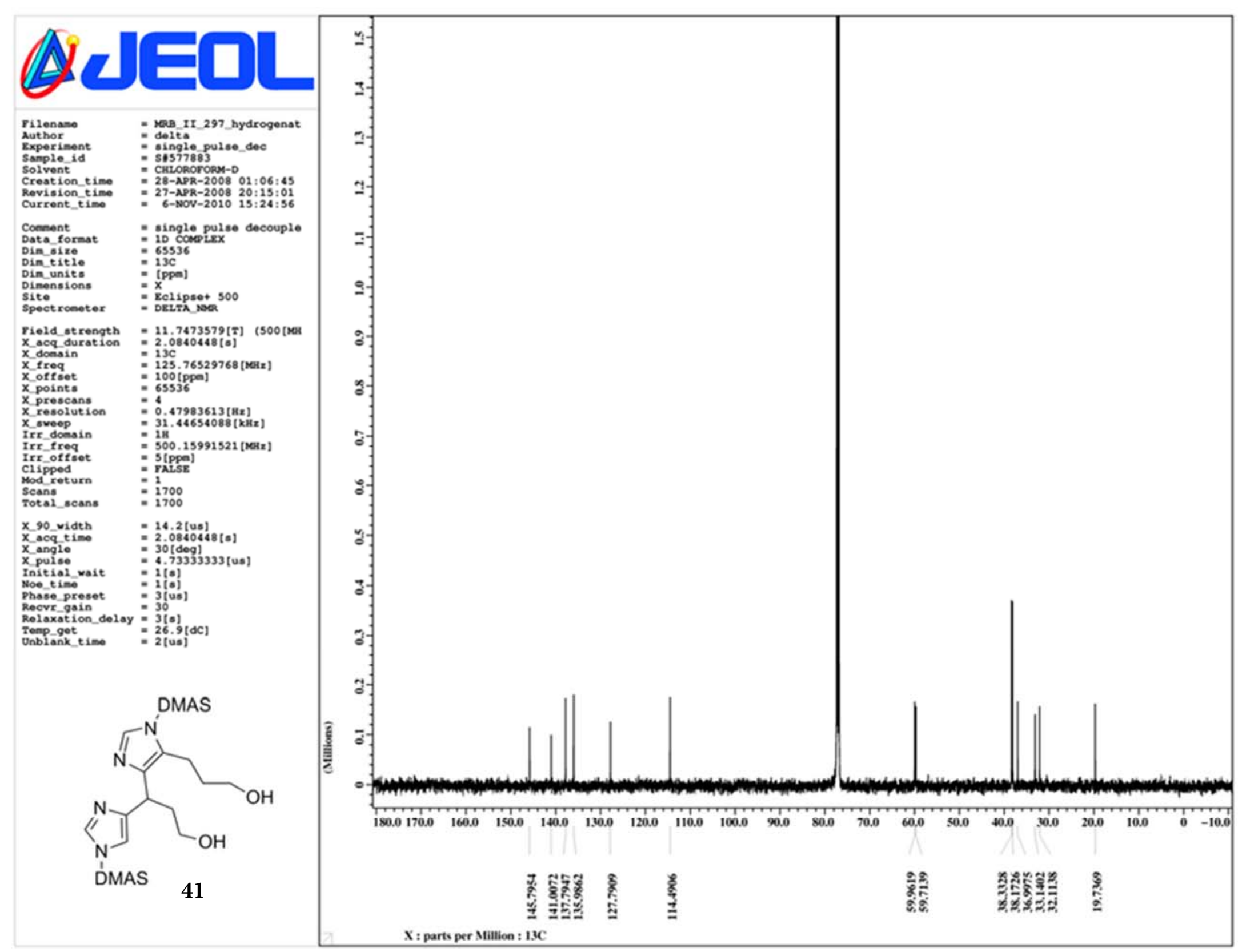




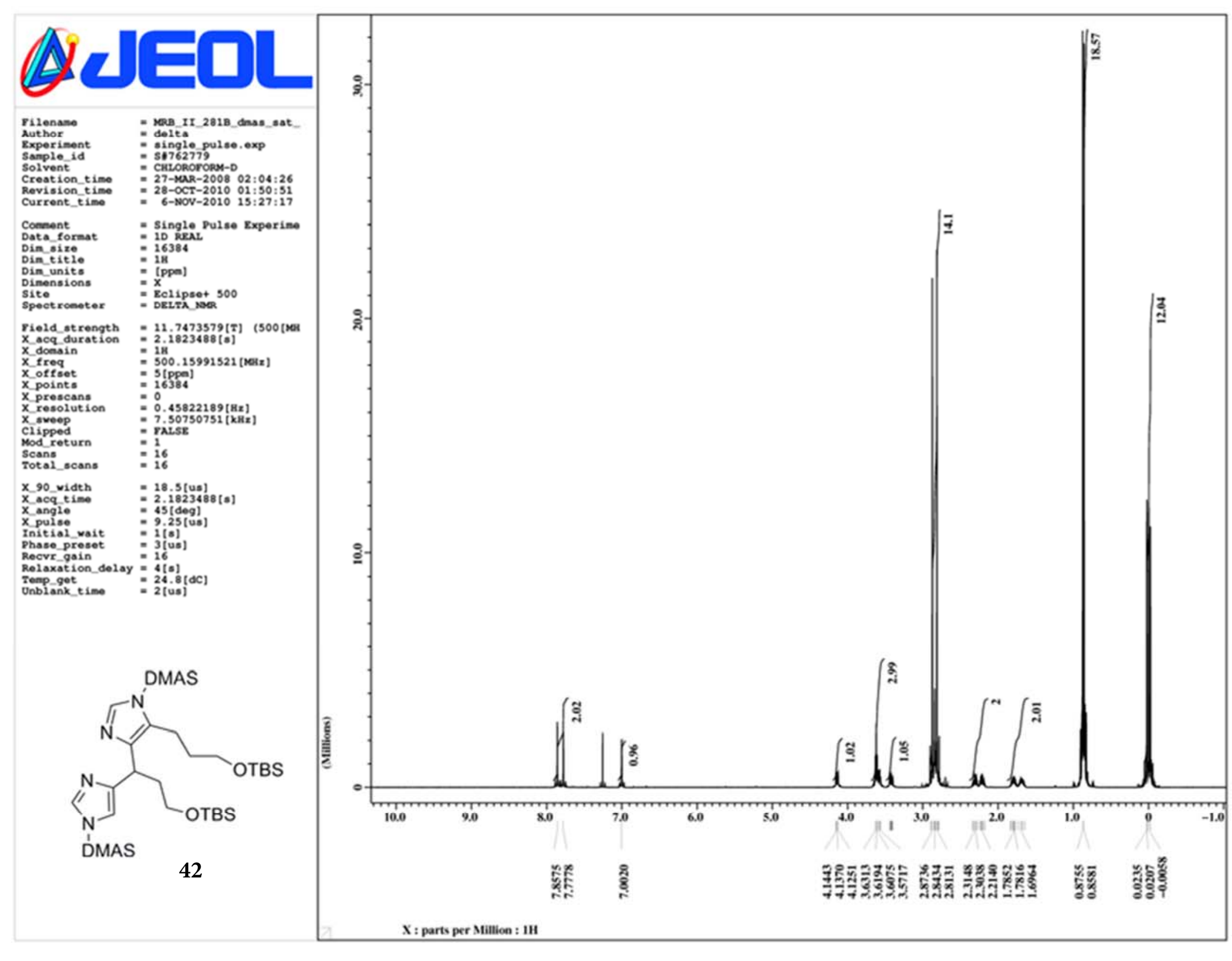




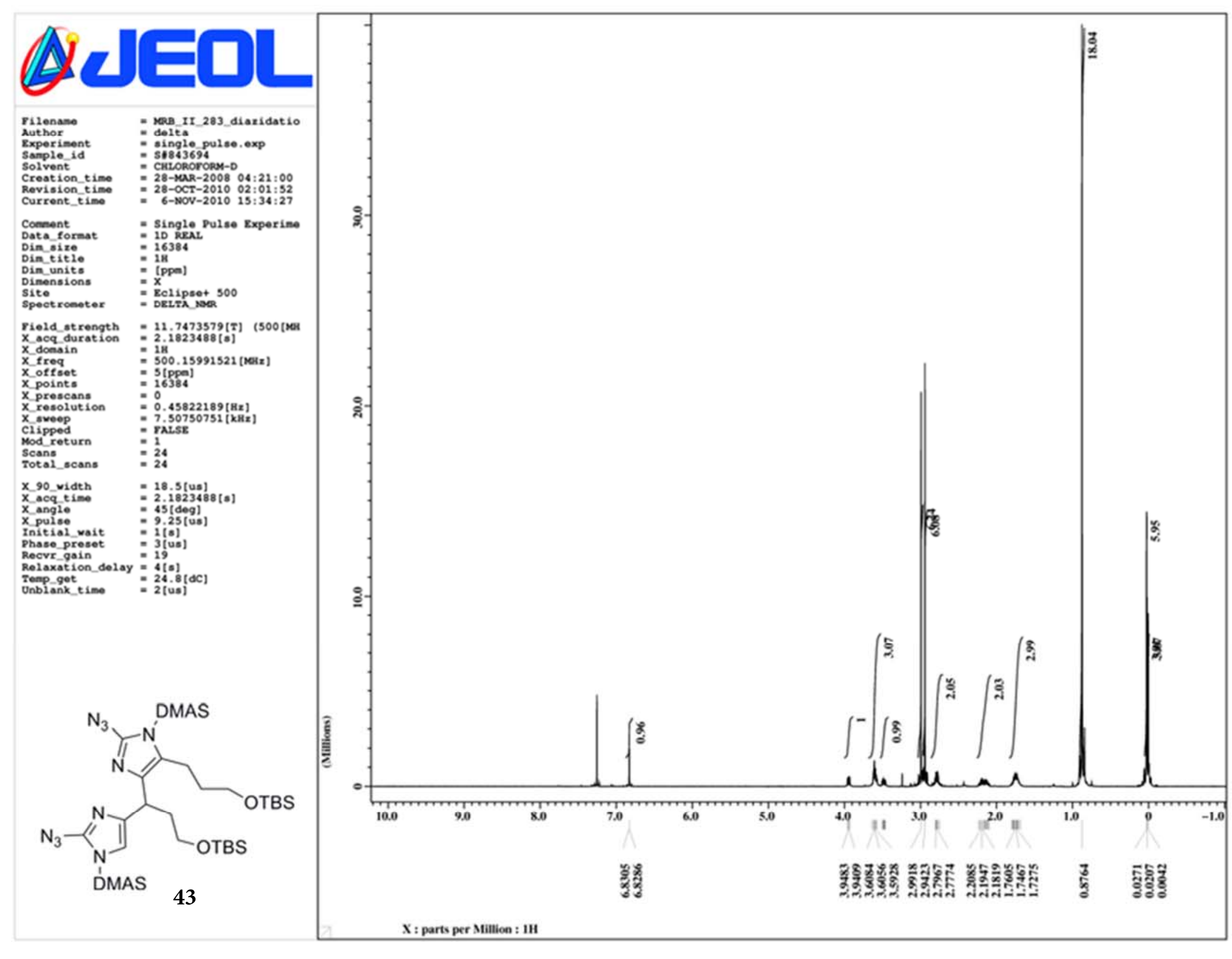




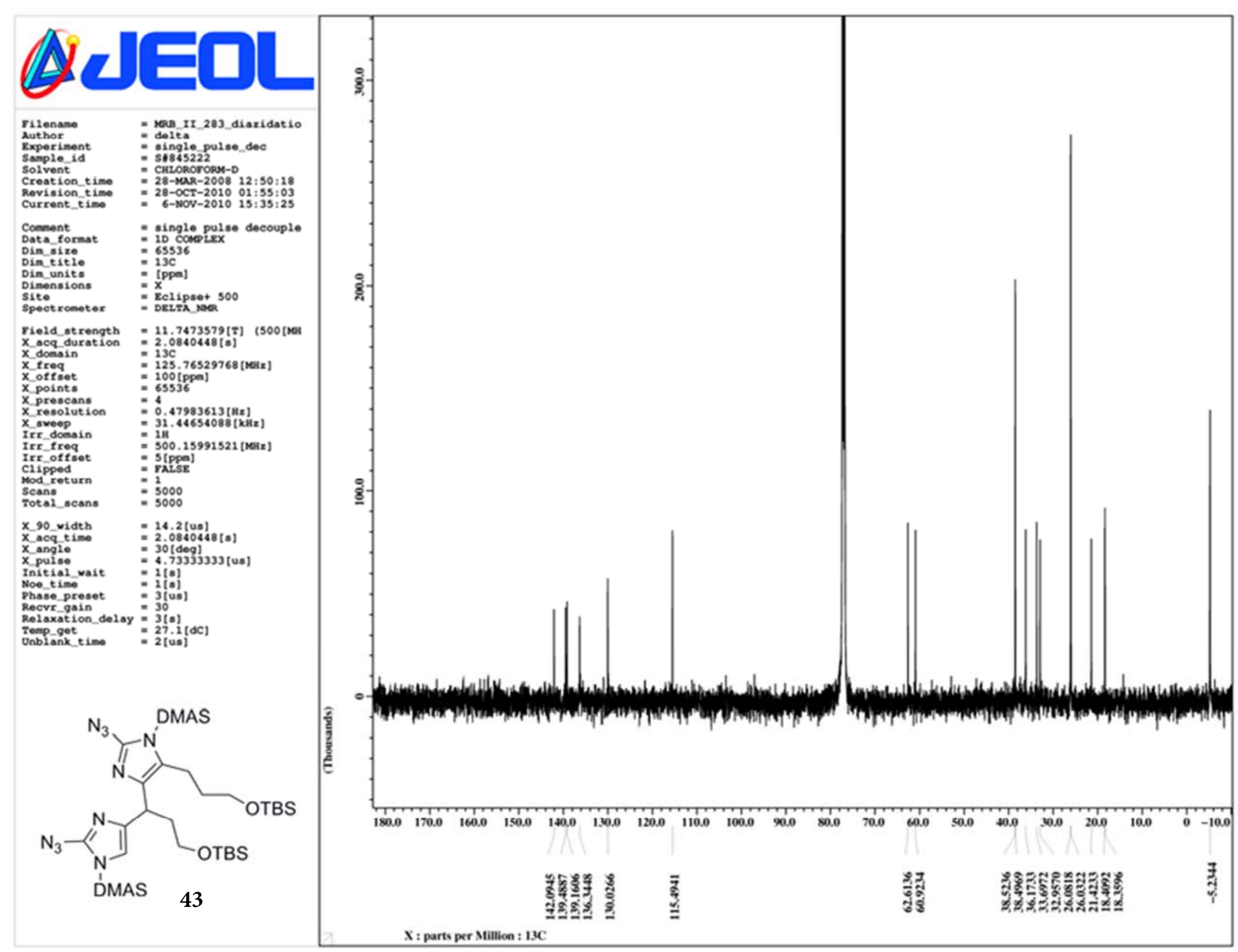




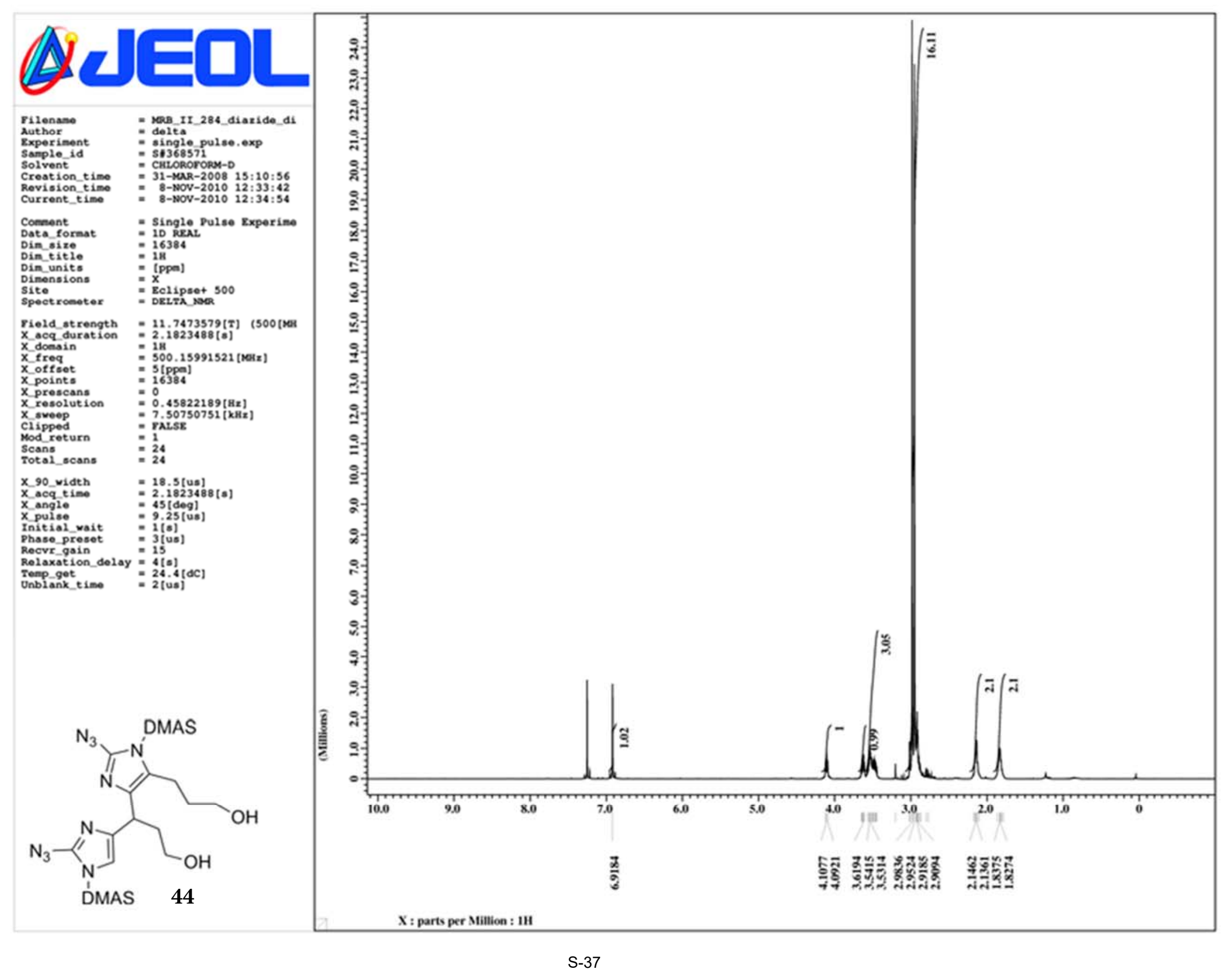




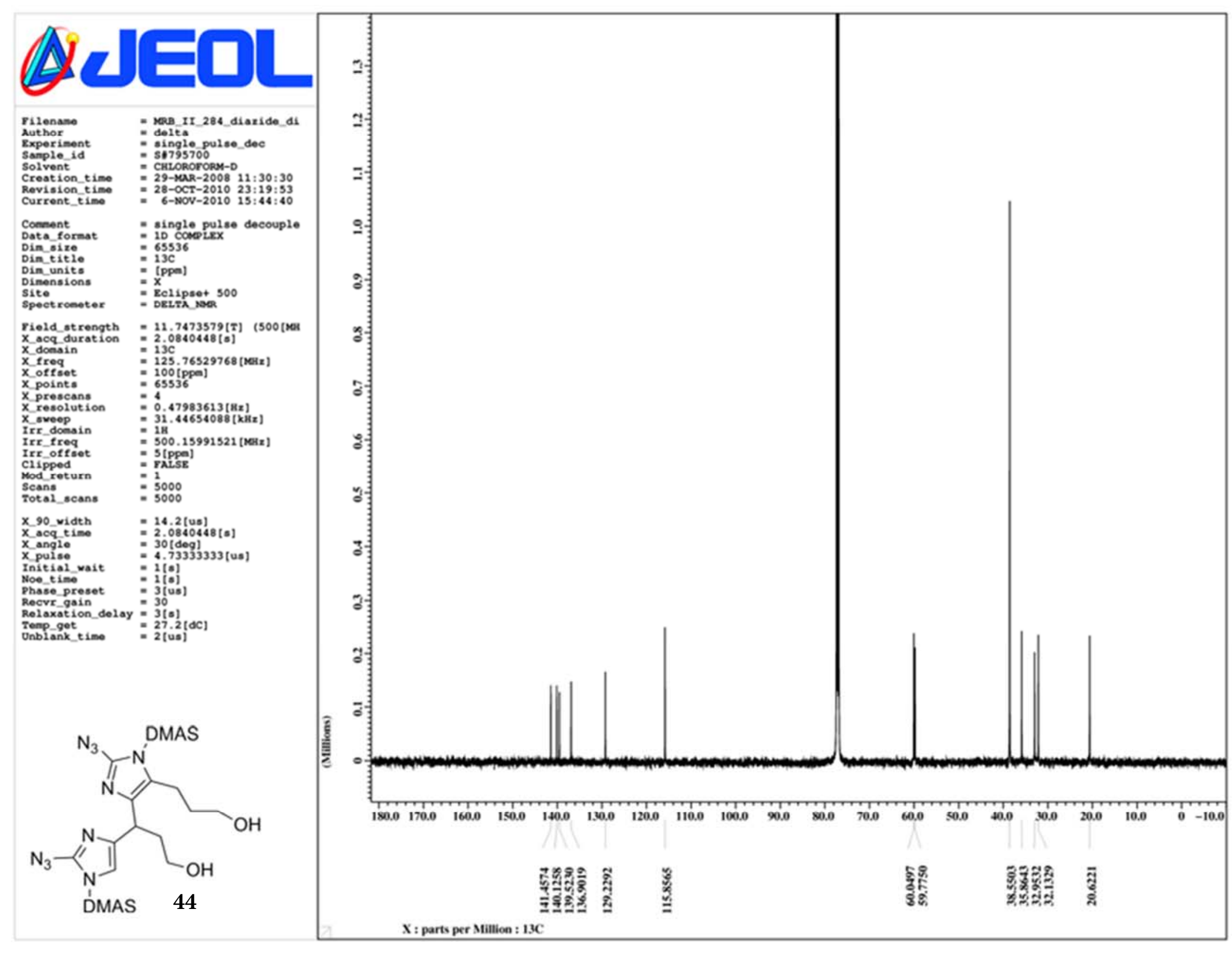




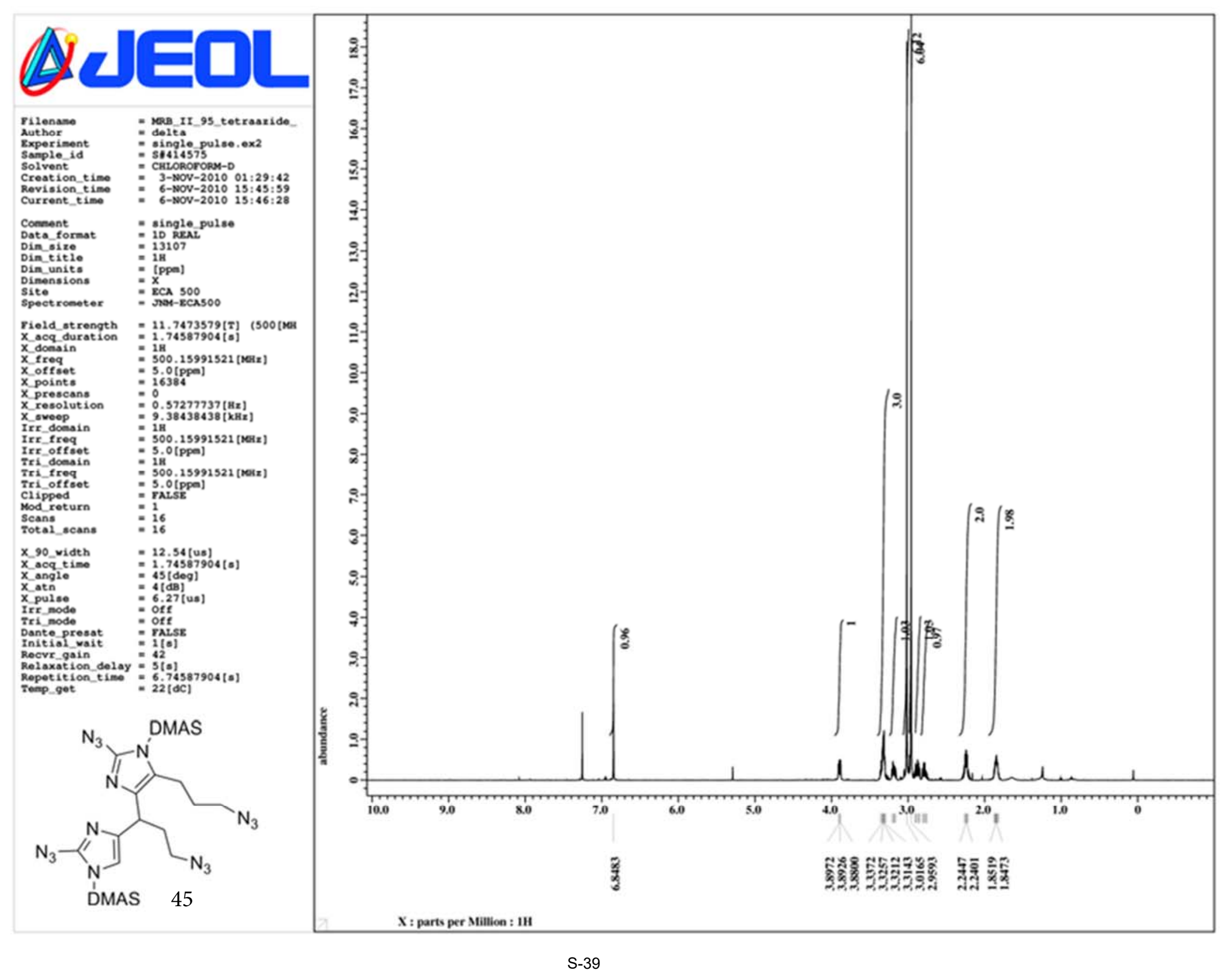




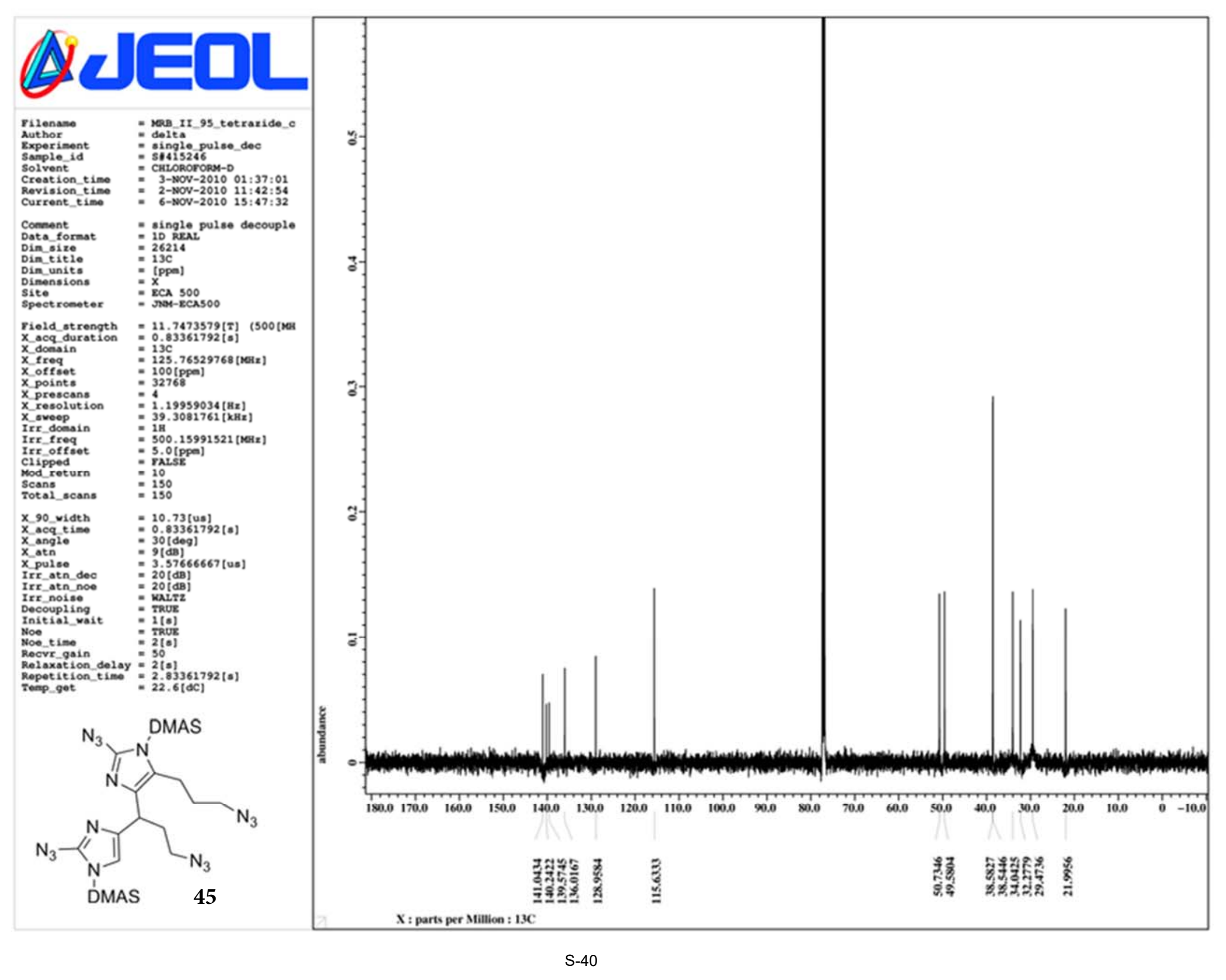




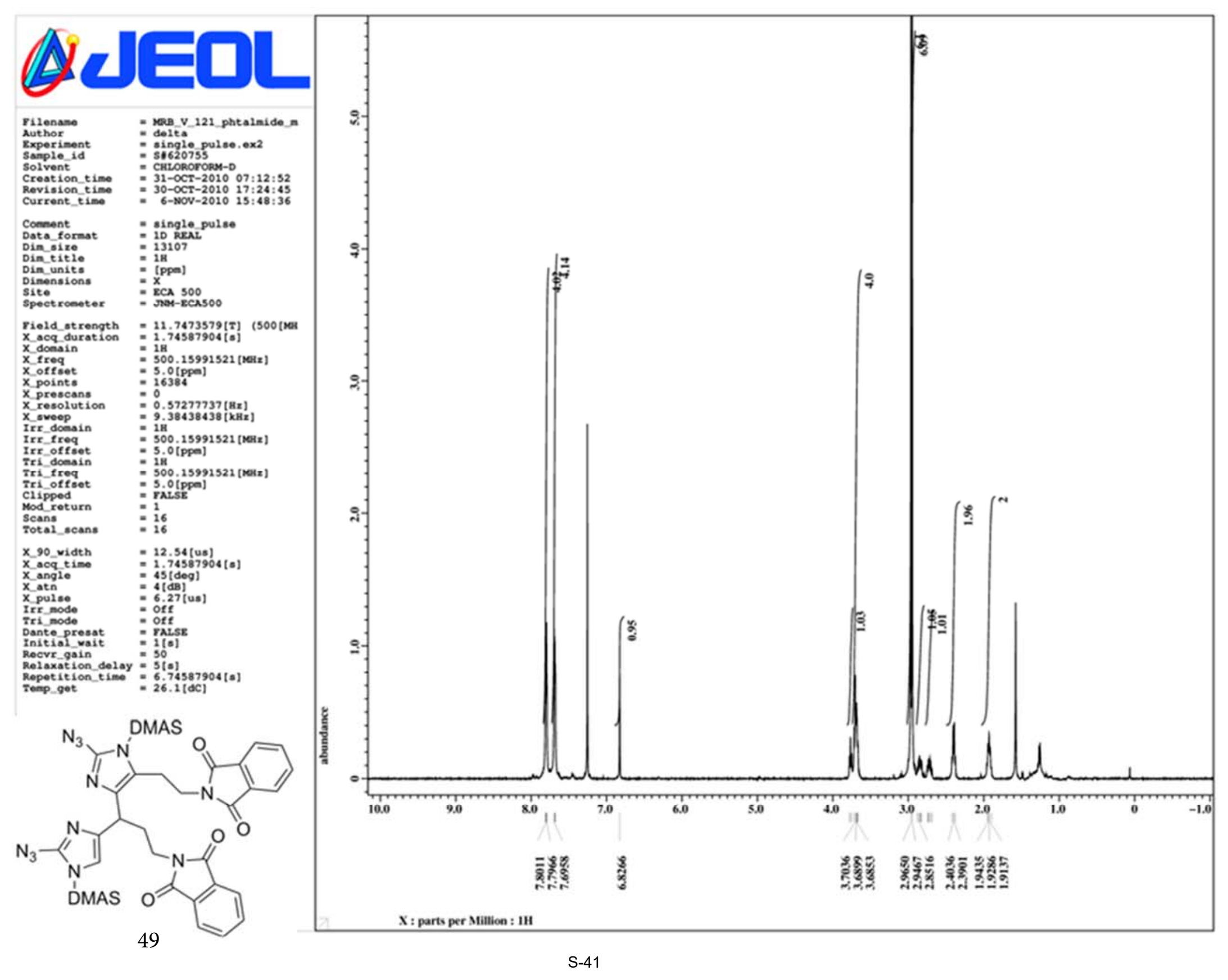




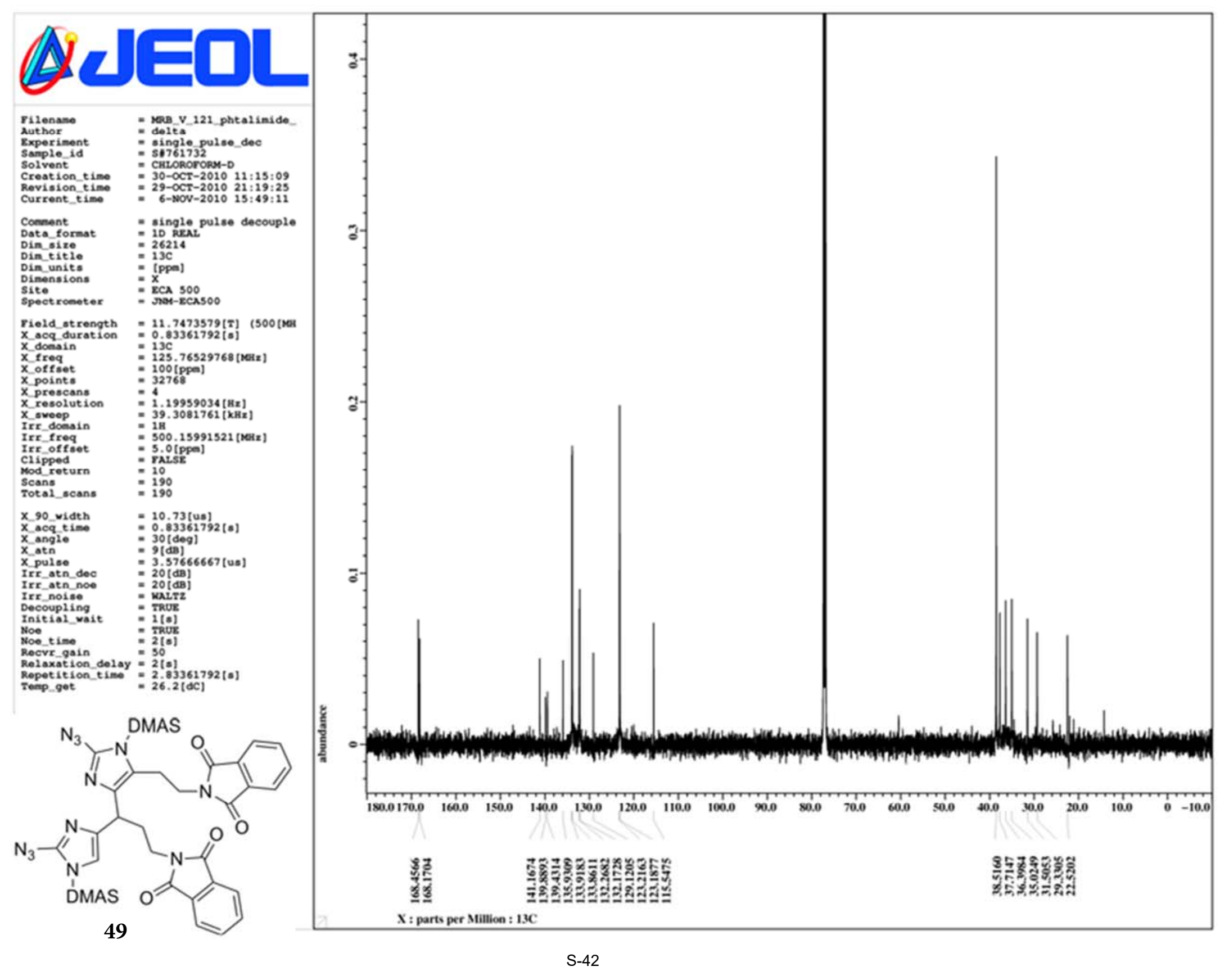




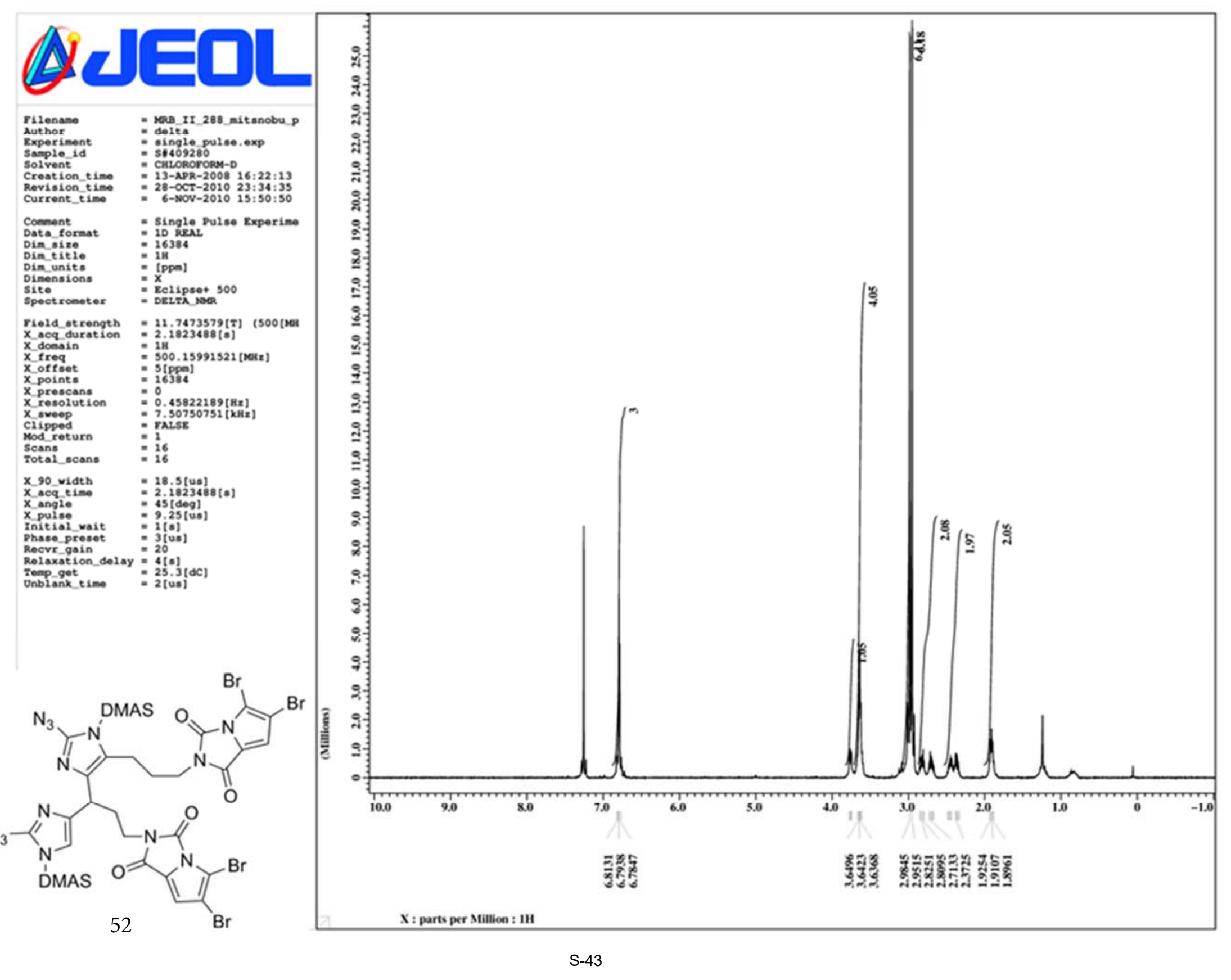




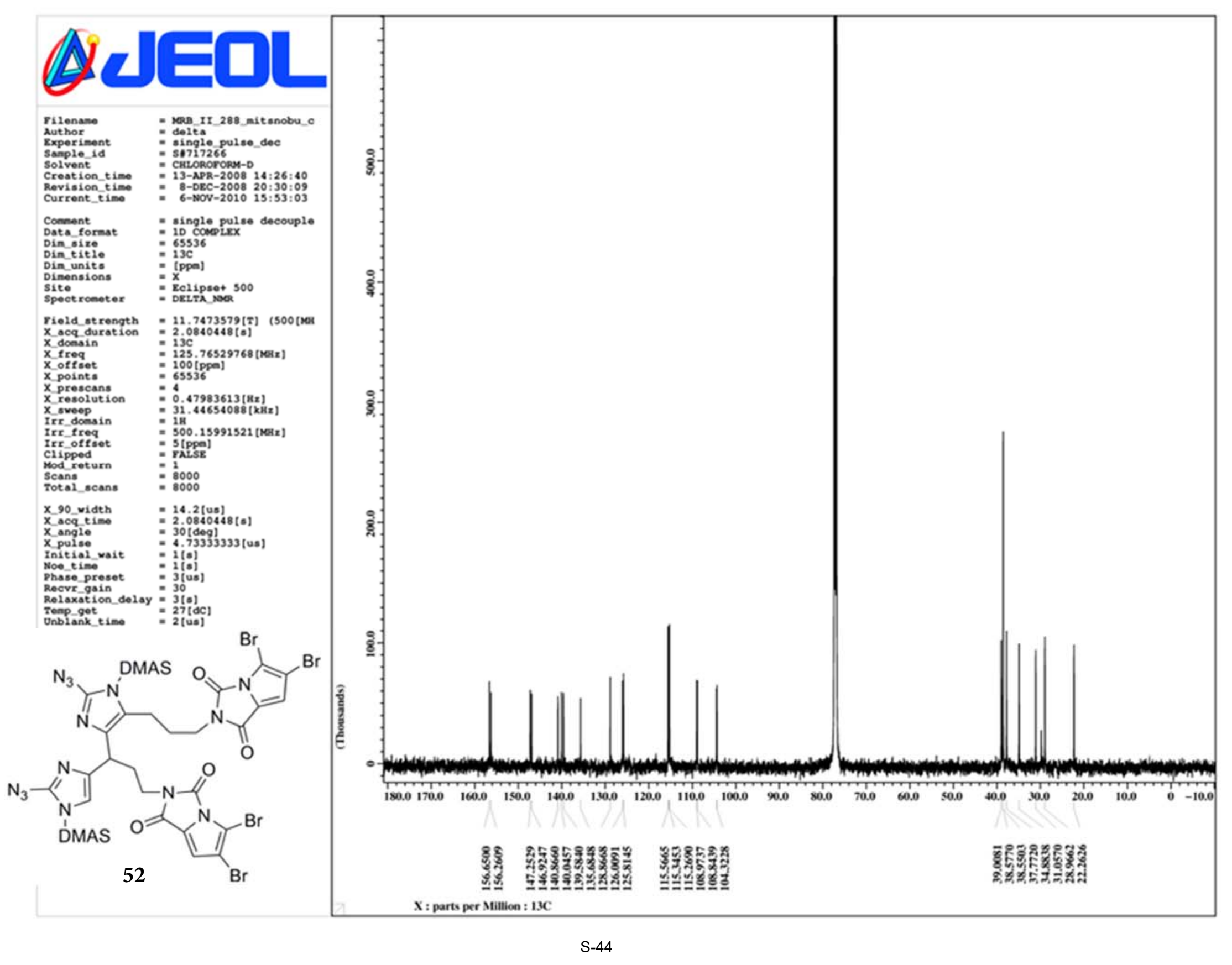




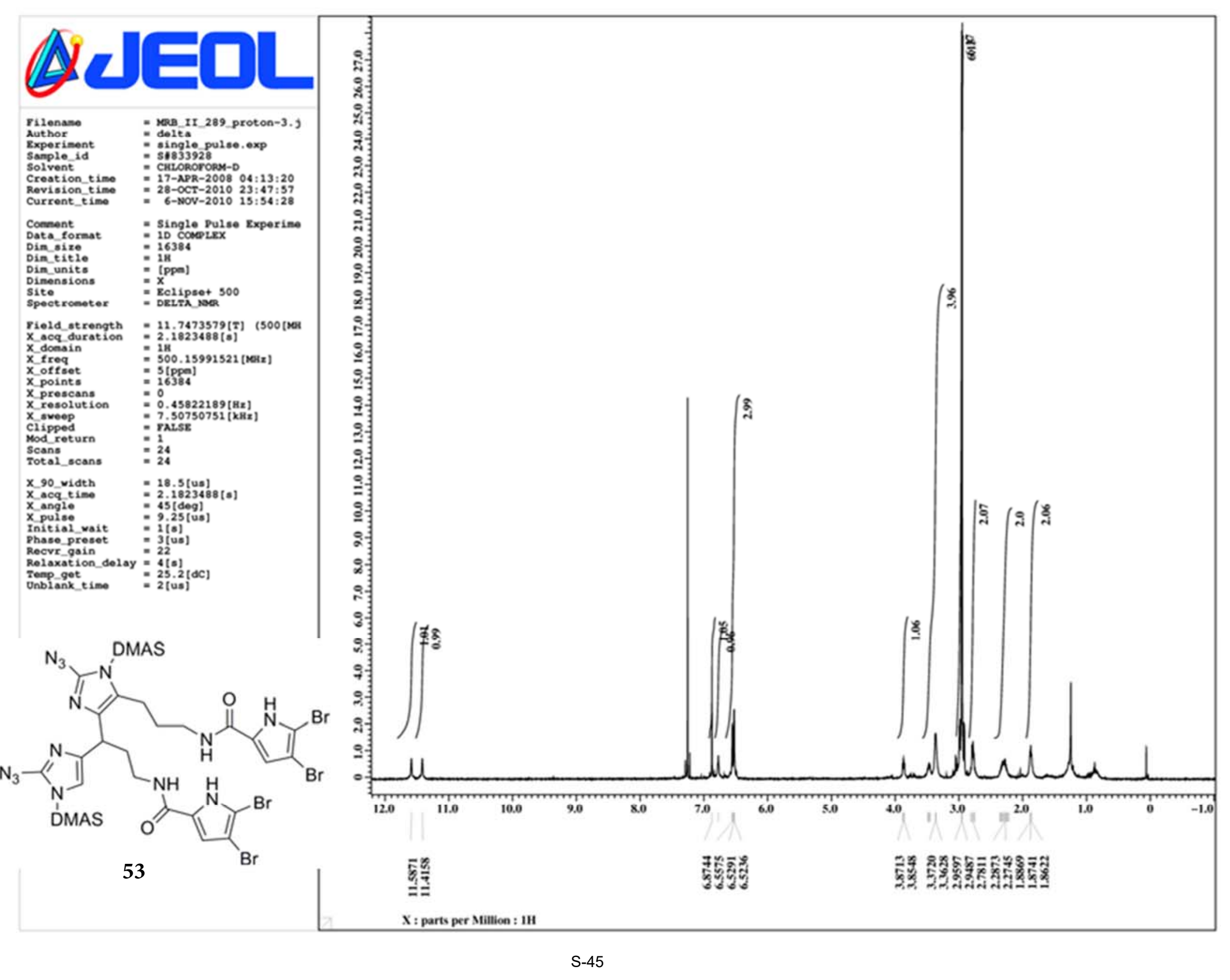




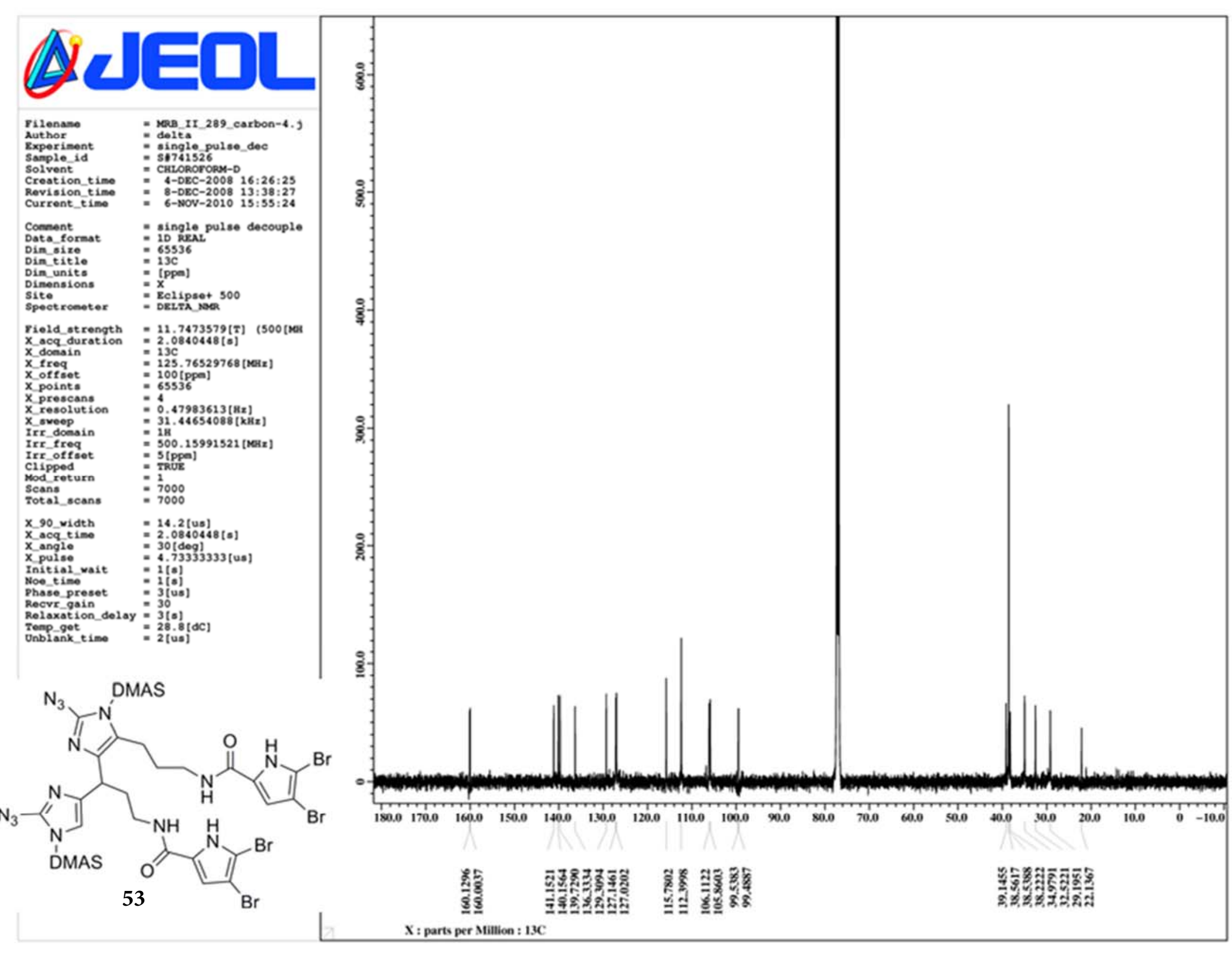




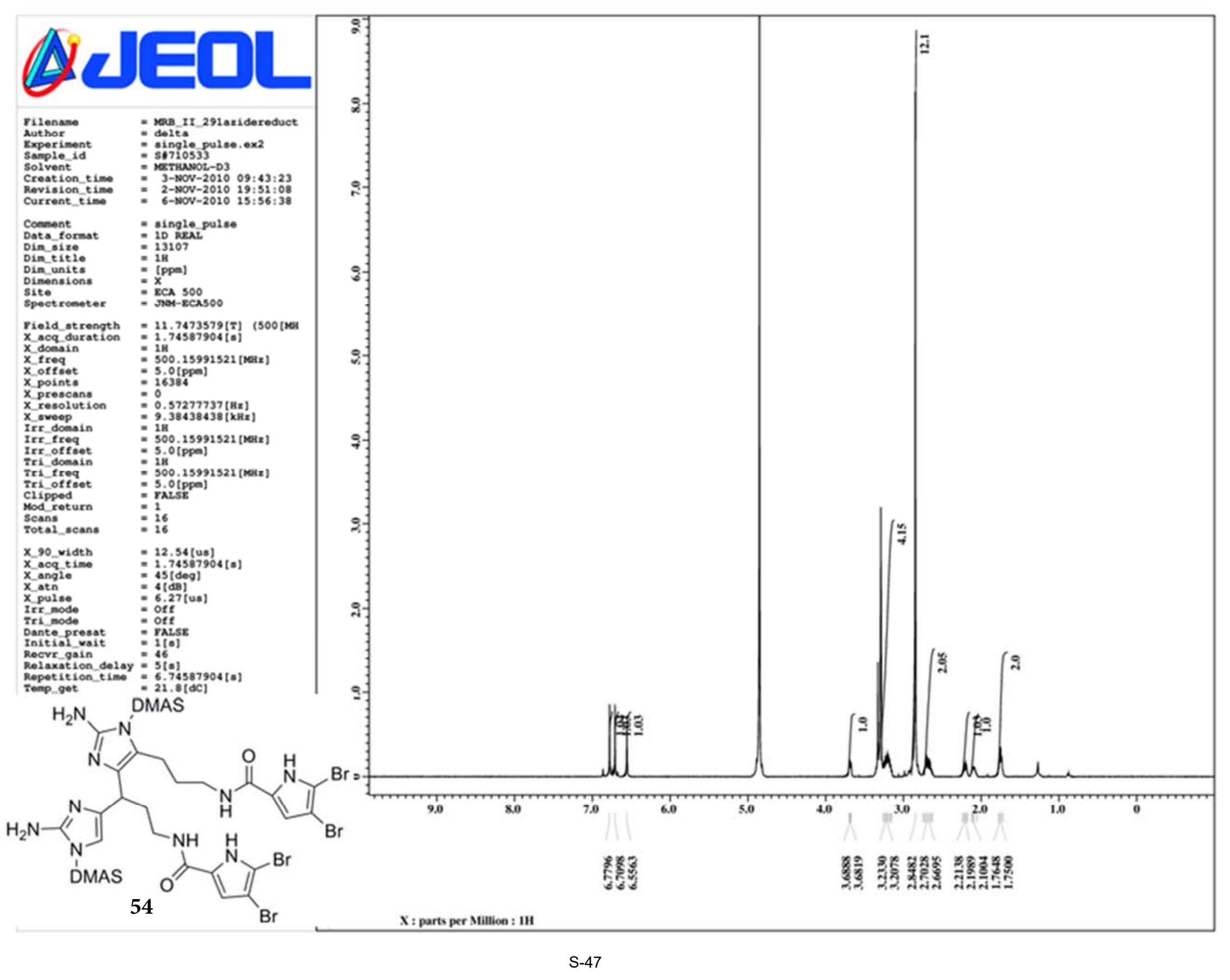




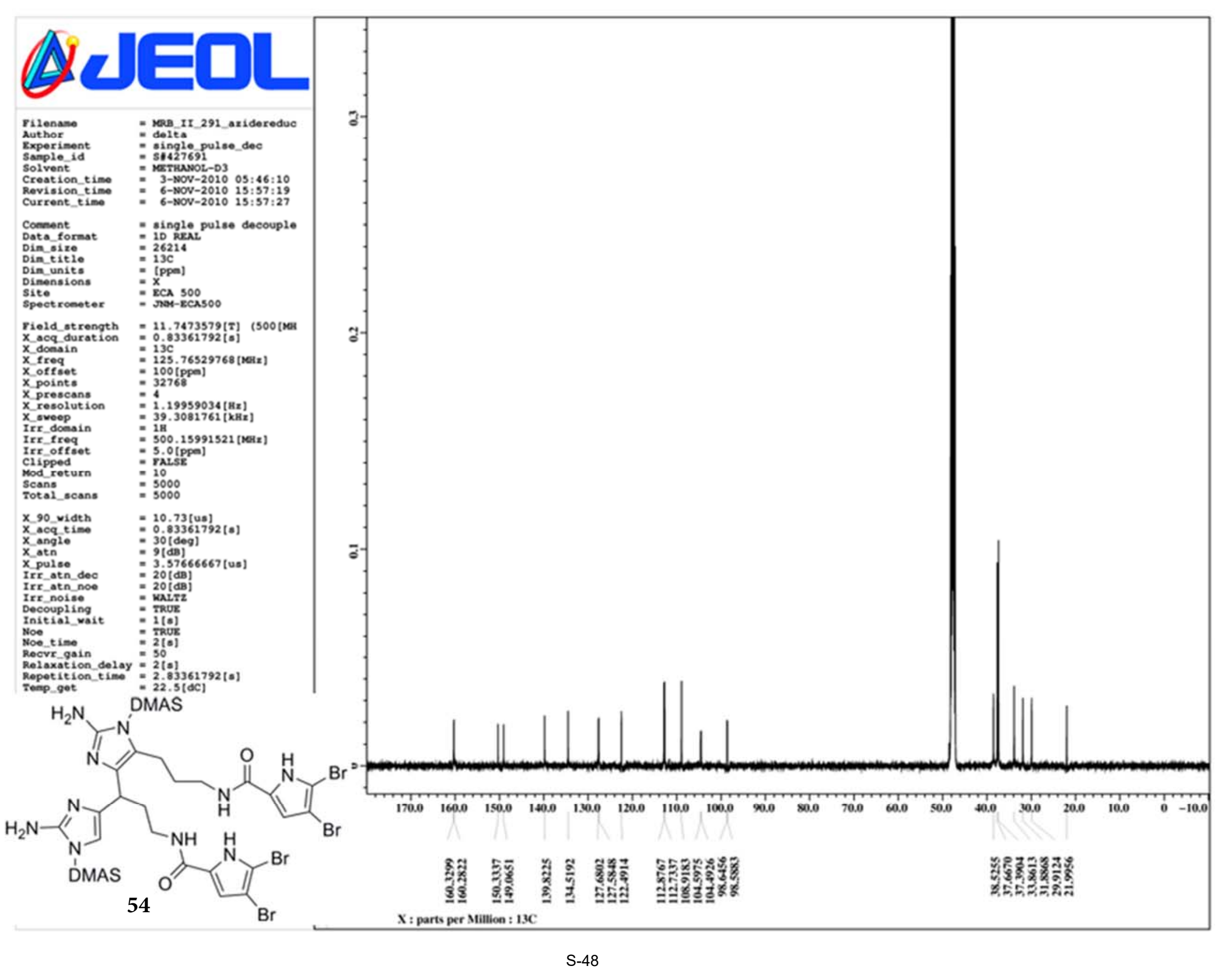




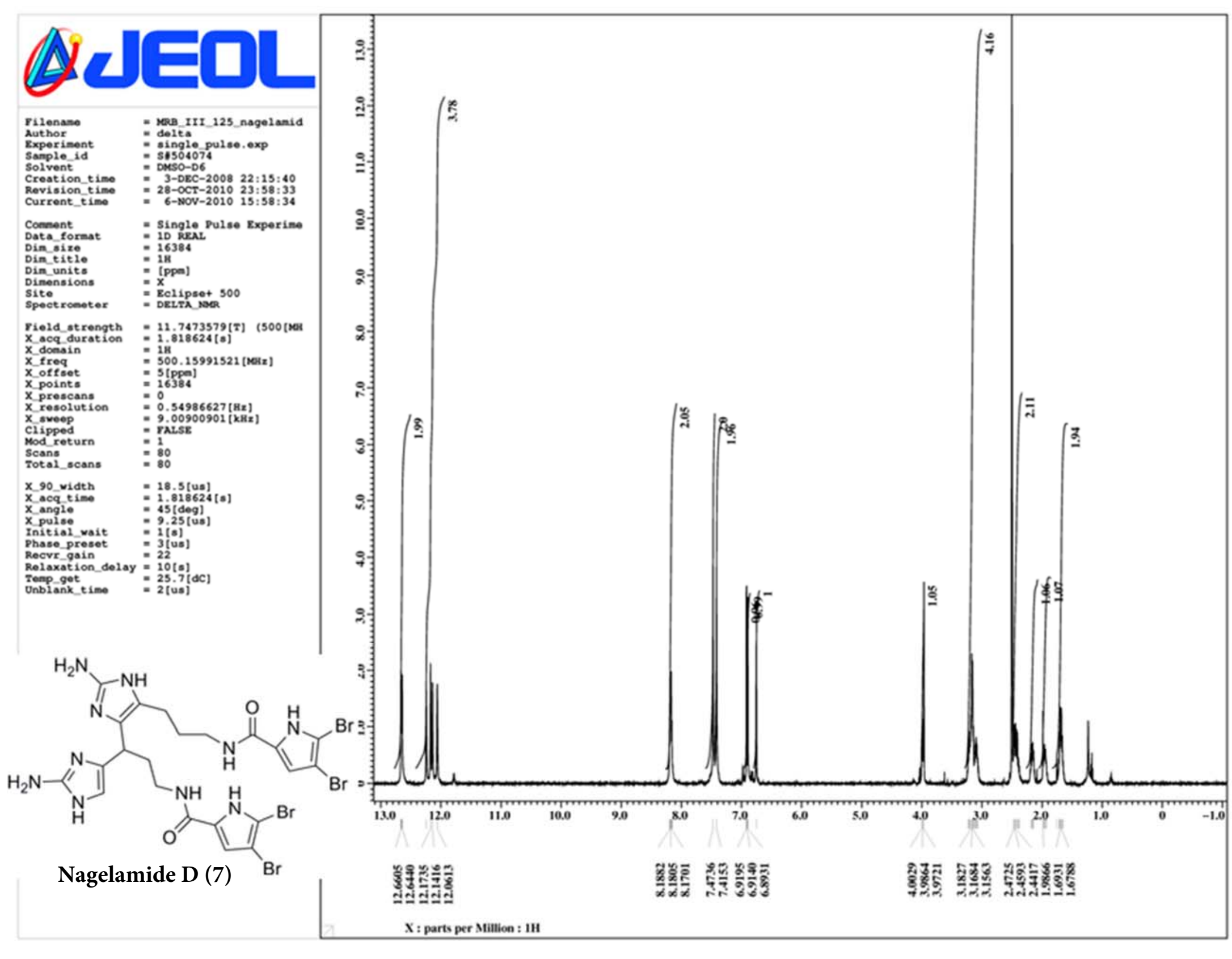




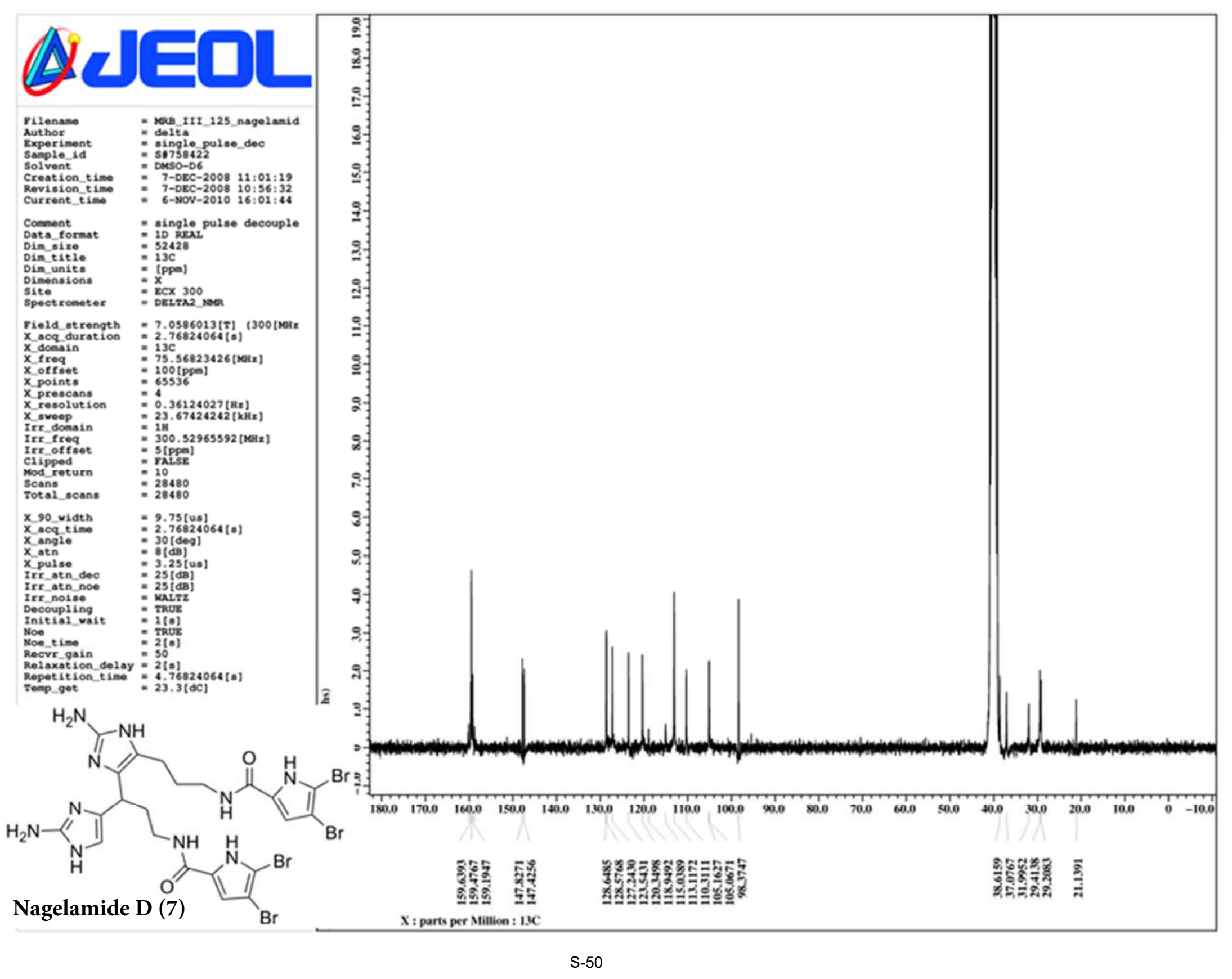




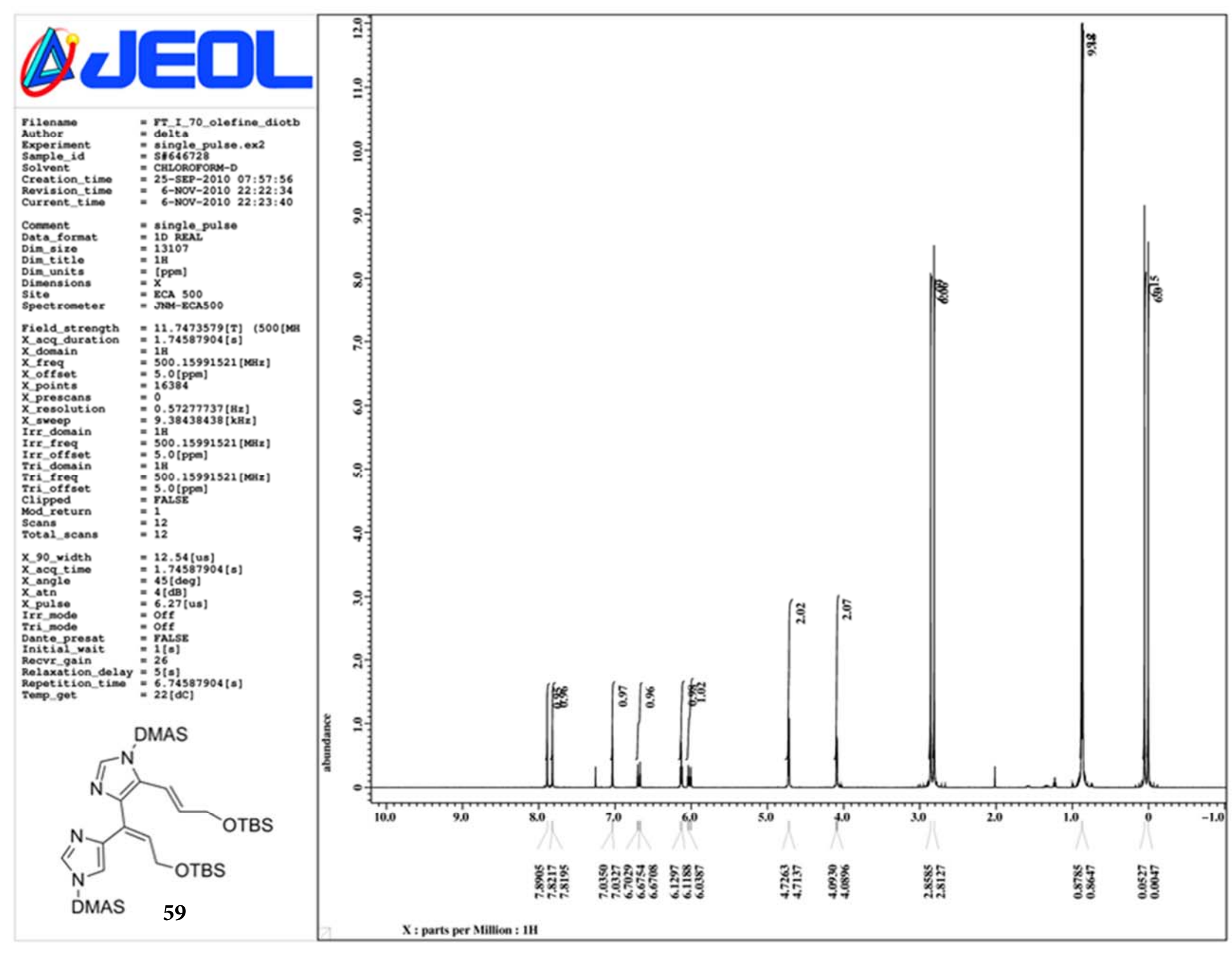




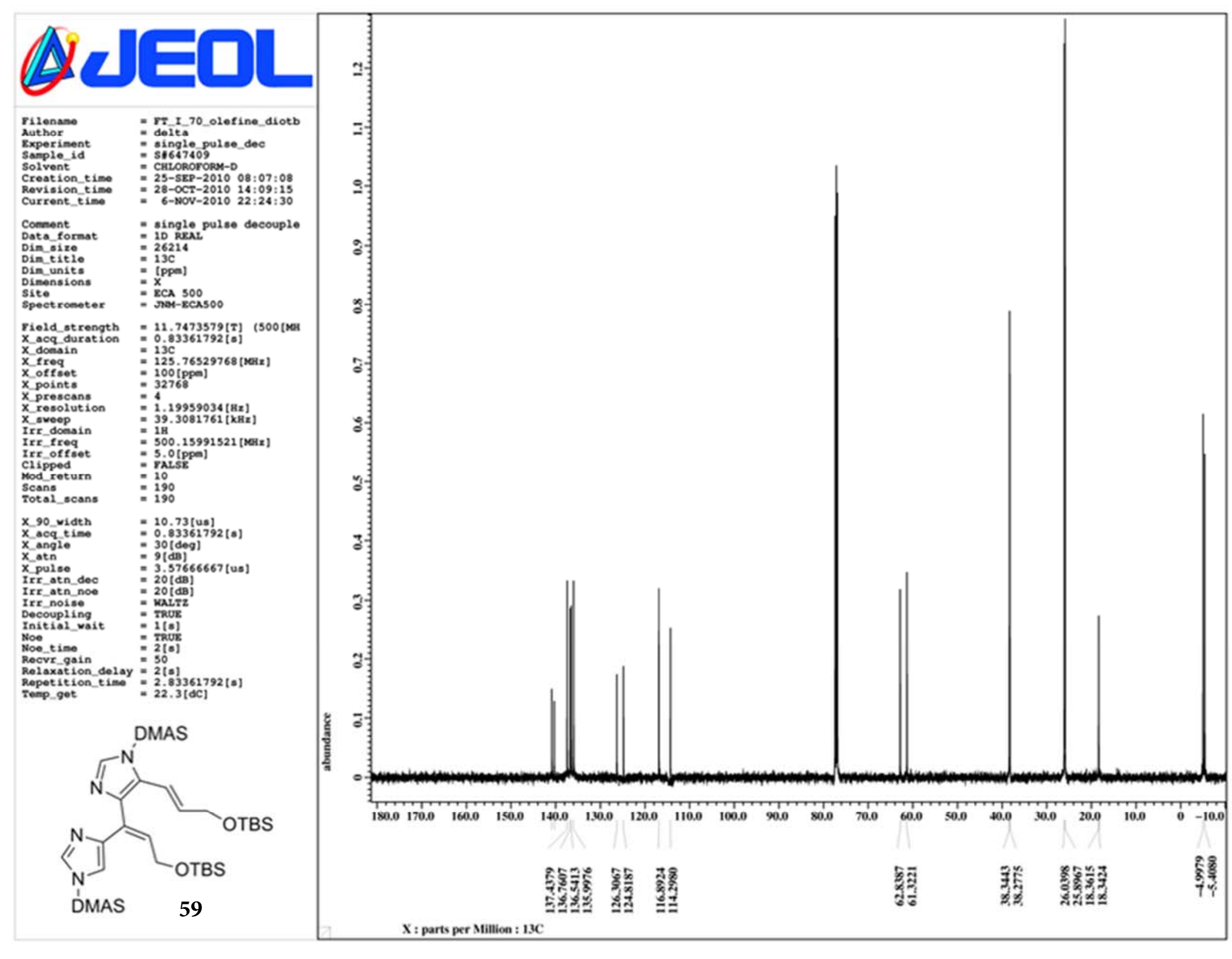




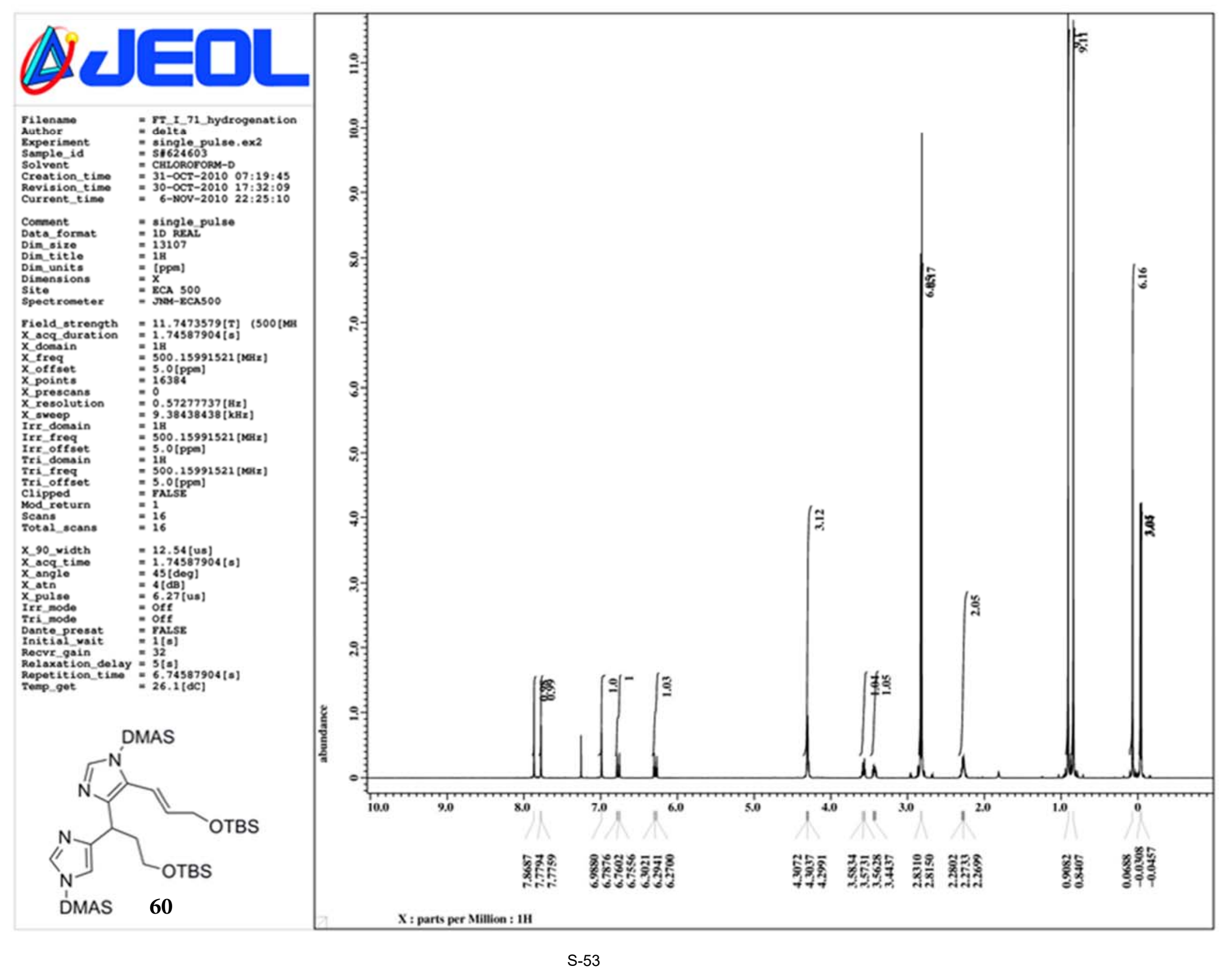




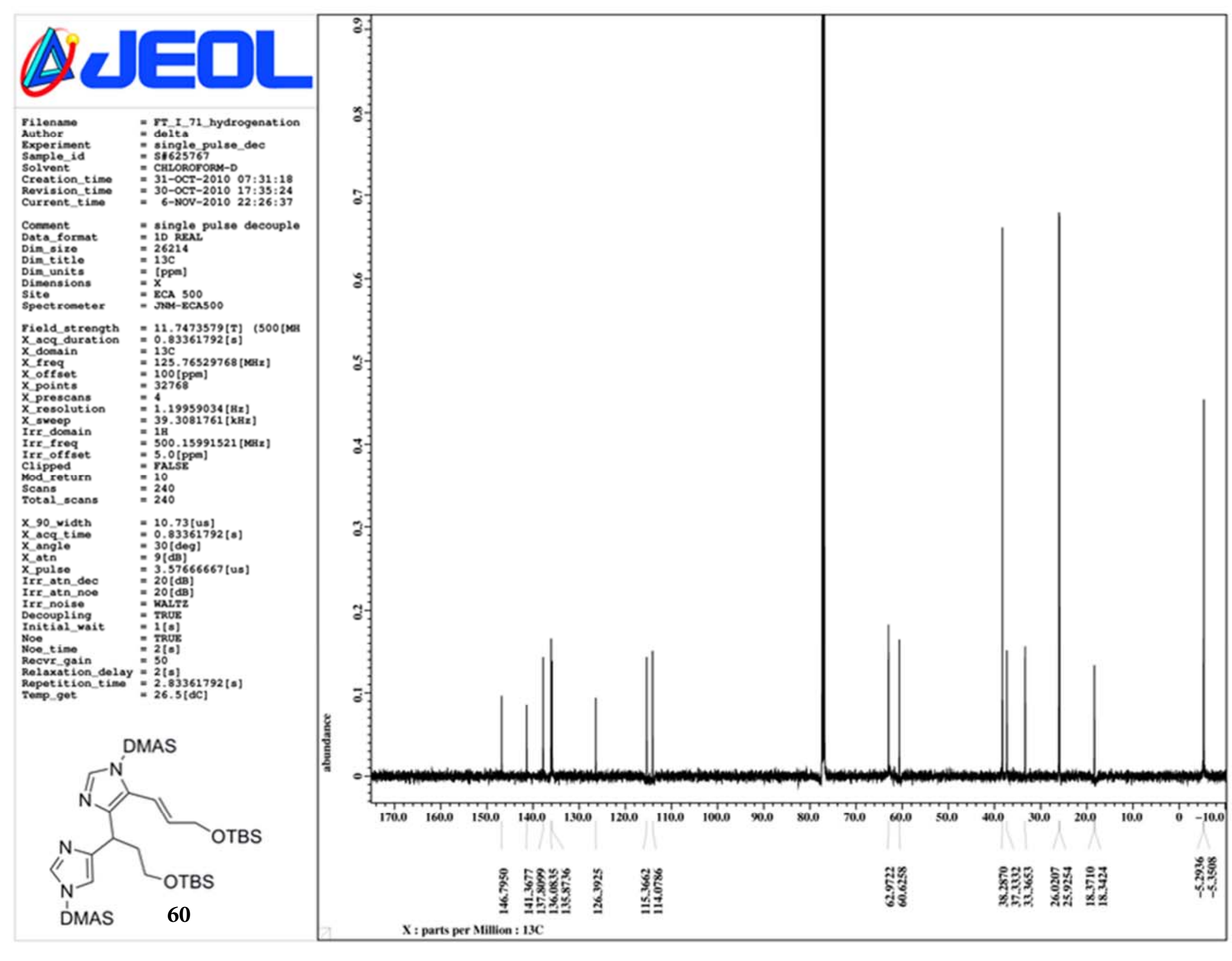




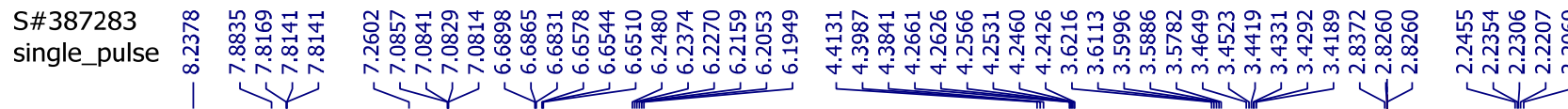

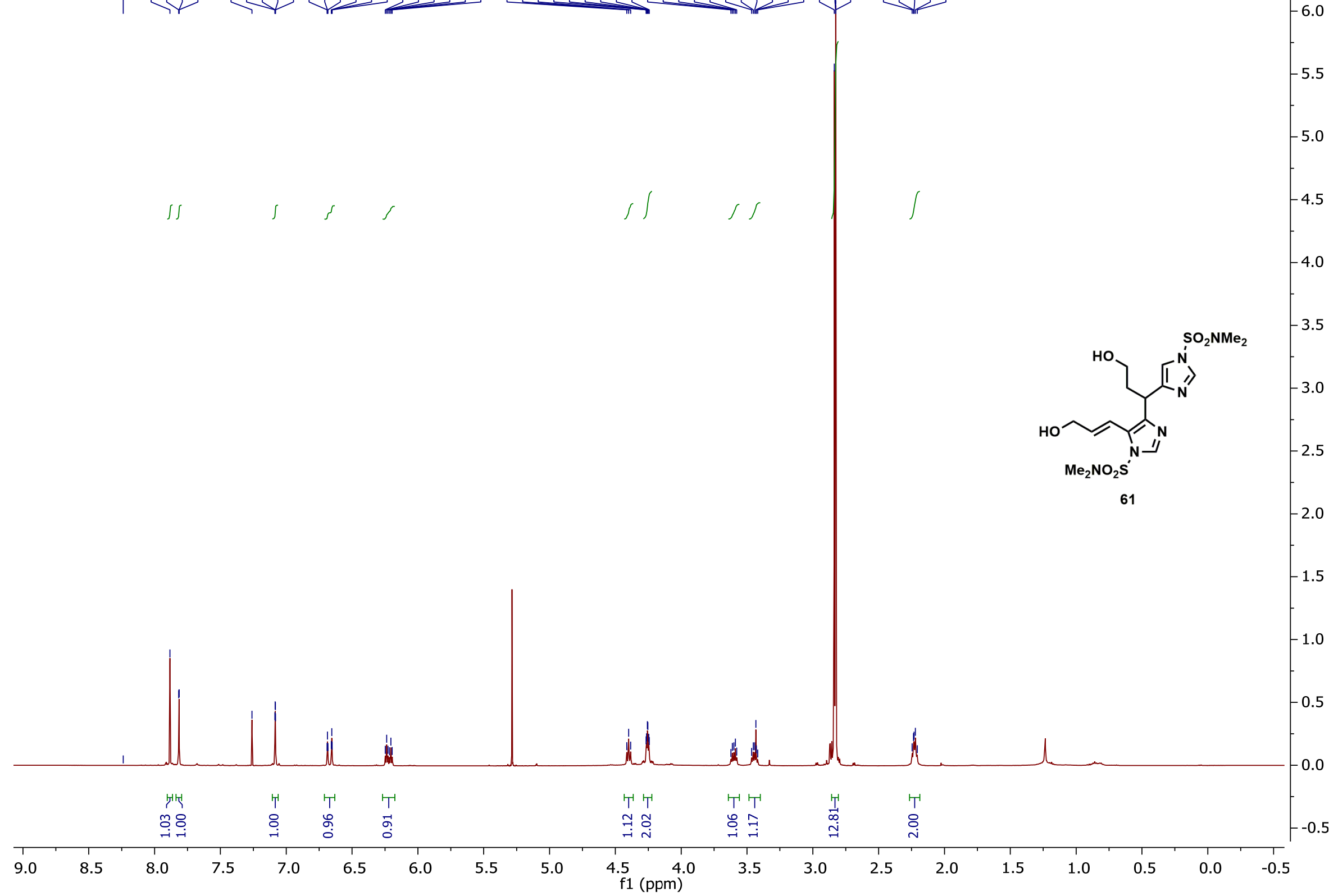


S\#390222

single pulse decoupled gated NOE

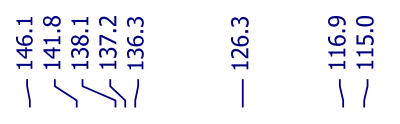

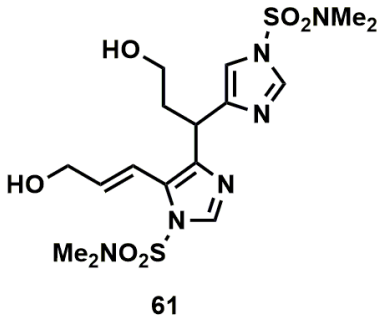




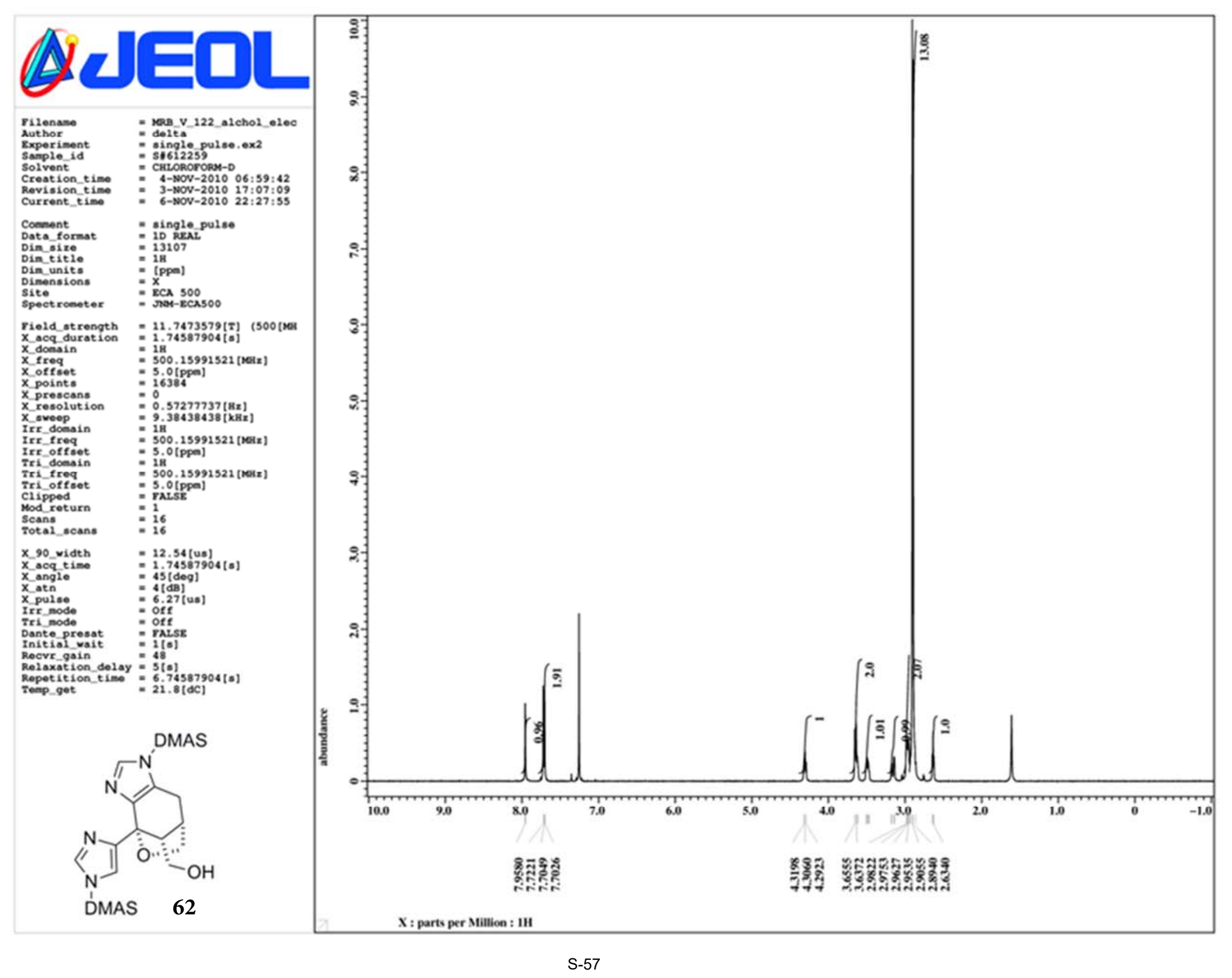




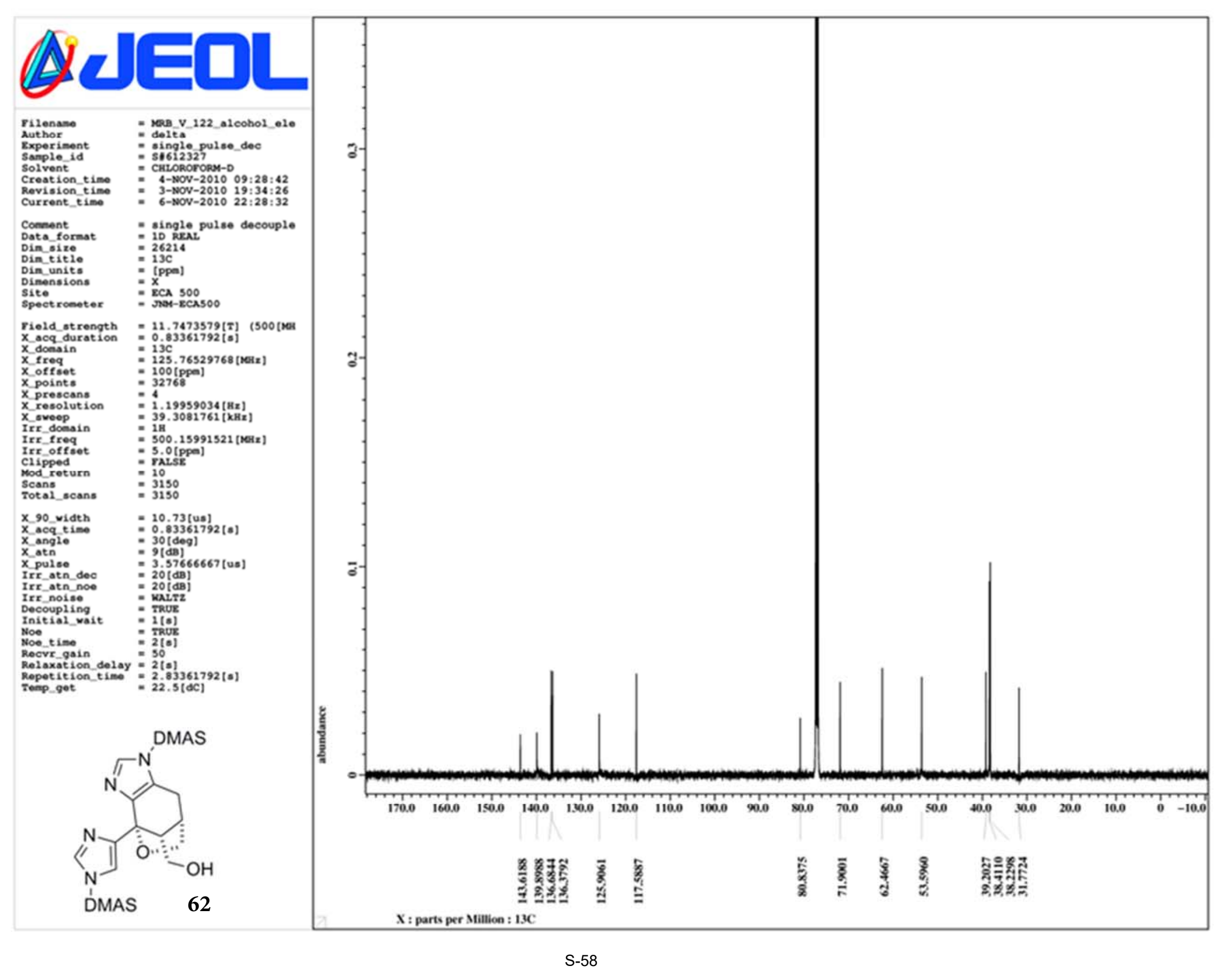




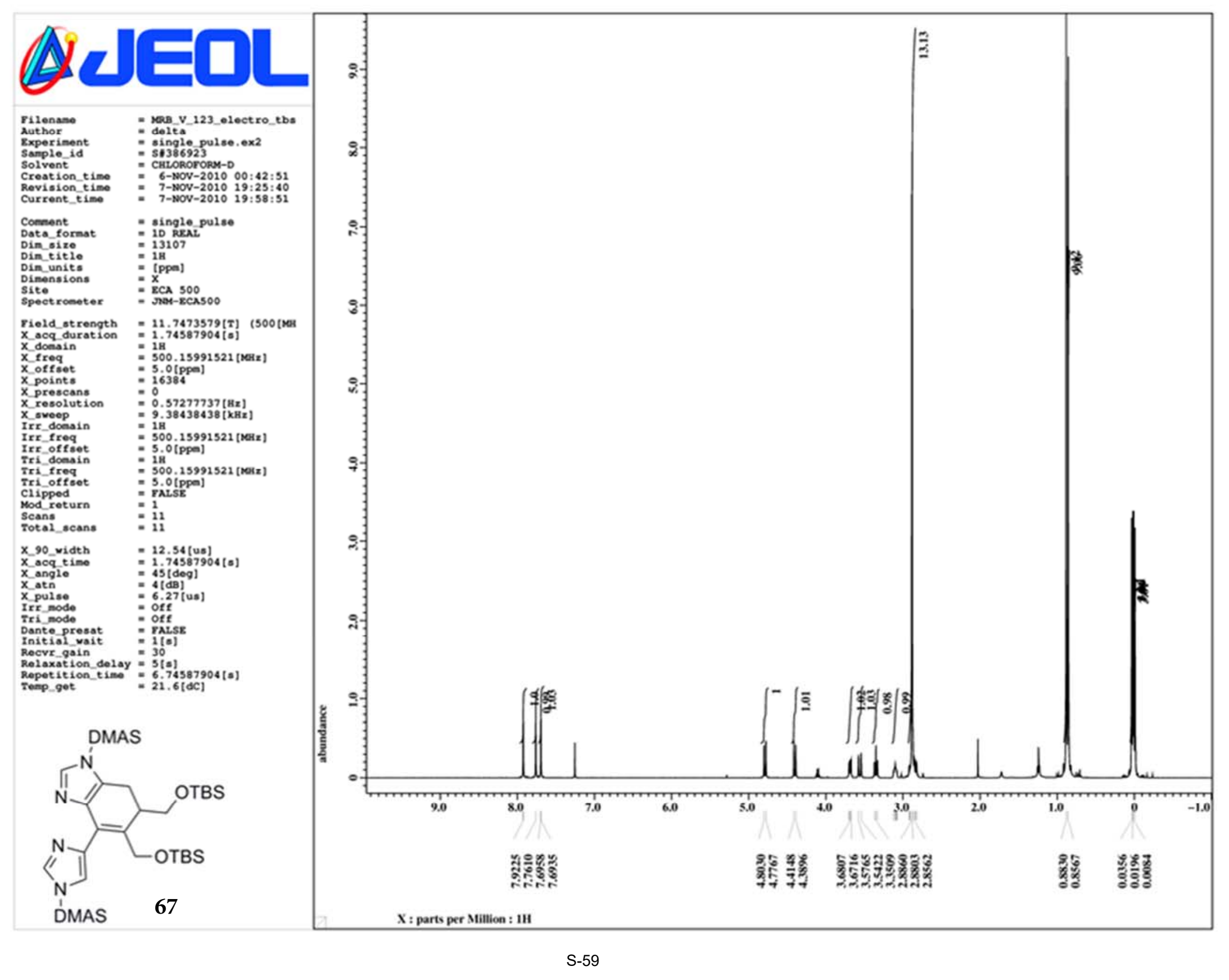




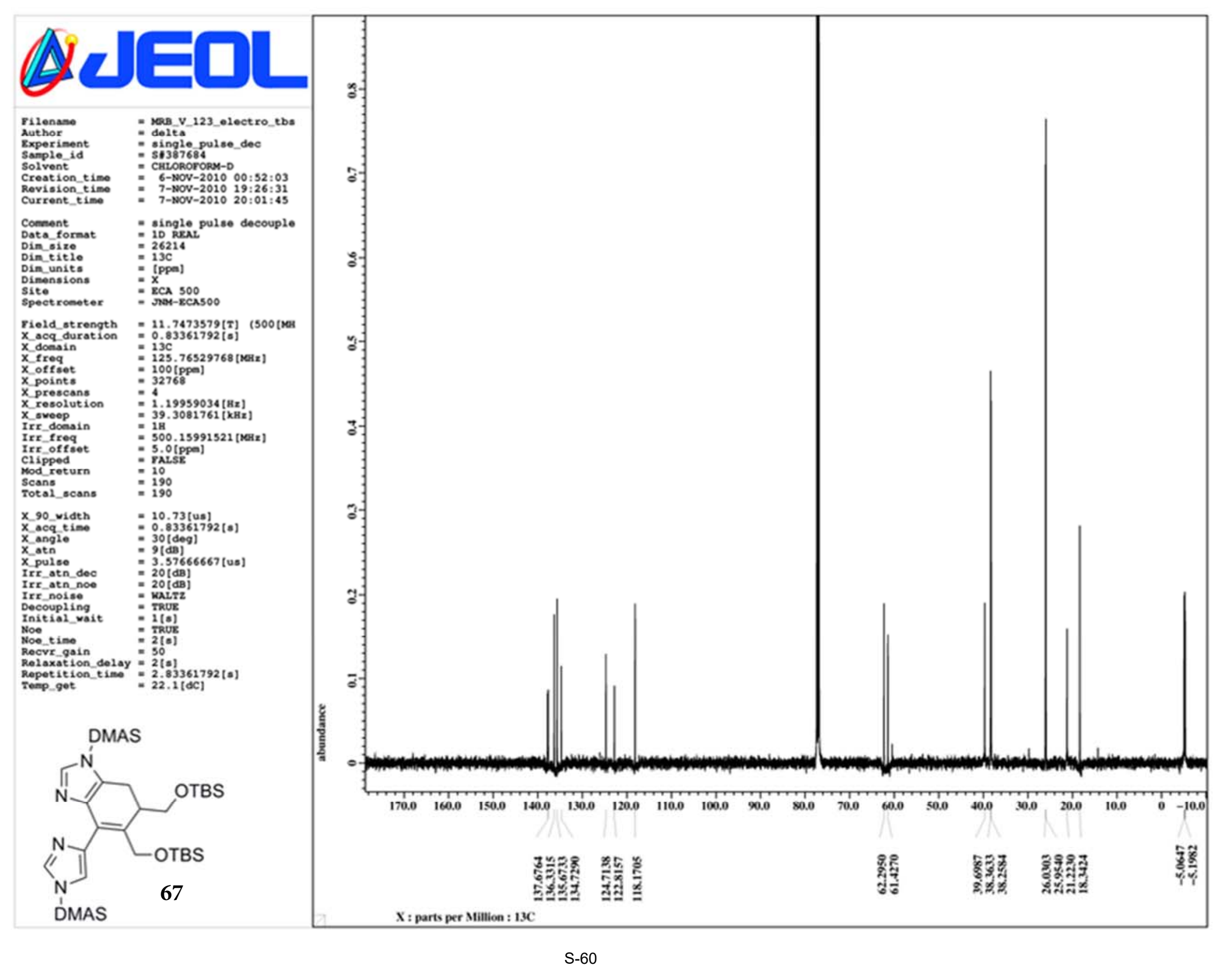

